\title{
Sismoestratigrafia da seção Campaniana-Maastrichtiana da Formação Calumbi no campo de Carapitanga (Bacia Sergipe-Alagoas)
}

\author{
Seismic stratigraphy of the Campanian-Maastrichtian section \\ of the Calumbi Formation in the Carapitanga field (Sergipe-Alagoas Basin) \\ Isabela Ramos Soares ${ }^{1}$ (D), Felipe Torres Figueiredo ${ }^{1}$ (D), Germán Meneses Hernández ${ }^{1}$ (D) \\ 1 Universidade Federal de Sergipe - UFS, Programa de Pós-Graduação em Geociências e Análise de Bacias, \\ Avenida Marechal Rondon, s/n, Jardim Rosa Elze, CEP 49100-000, São Cristóvão, SE, BR \\ (soares.isabelar@gmail.com; ftfigueiredo@gmail.com; germanmeneher77@gmail.com).
}

Recebido em 14 de abril de 2019; aceito em 21 de outubro de 2019

\begin{abstract}
Resumo
A Formação Calumbi tem parte de suas reservas de petróleo e gás preservada no campo de Carapitanga em rochas de idade Campaniana-Mastrichiana da Bacia de Sergipe-Alagoas, produtor de acumulação marginal da área norte da bacia. Apesar de seu importante papel na produção regional de hidrocarbonetos, as sequências deposicionais do campo têm sido pouco discutidas na academia. Com o objetivo de contribuir para os modelos de sequências deposicionais do Cretáceo Superior, analisou-se a sísmica disponível do campo sob a ótica dos conceitos de Estratigrafia de Sequências. Os resultados obtidos sugerem três sequências deposicionais de curta duração (3 - $10 \mathrm{Ma})$, com desequilíbrio entre subidas e quedas entre si, o que contrasta com as premissas dos modelos de sequências. Estas se distribuem em três cânions com até $10 \mathrm{~km}$ de largura, 282, 202 e 102 m de espessura, respectivamente, situadas na transição Pré-Campaniano-Campaniano, Campaniano e Mastrichiano. A primeira sequência é formada por quatro tratos de sistema, com pequeno desequilíbrio entre dois eventos transgressivos de menor duração em relação a dois eventos regressivos, que registram a sedimentação dos tratos de mar baixo e transgressivo, correspondendo aos melhores candidatos a rochas-reservatório do campo. A segunda sequência, mais jovem, preserva três eventos de regressão e um de transgressão; e a terceira sequência tem comportamento similar, porém com maior duração de queda. O padrão de variação do nível de base é pouco harmônico e contrasta com a curva senoide adotada para predição de geometrias deposicionais em bacias de margens passivas e com os modelos interpretados ao norte da bacia, no qual foram identificadas quatro sequências. Os cinco picos de queda registrados parecem estar relacionados às flutuações glacioeustáticas de alta frequência do Cretáceo Superior.
\end{abstract}

Palavras-chave: Formação Calumbi; Estratigrafia de sequências; Variações do onlap costeiro; Cânions submarinos.

\begin{abstract}
Oil and gas reserves from Calumbi Formation are partially preserved in the Carapitanga field, mostly in deposits of Campanian and Maastrichtian age rocks of the Sergipe-Alagoas Basin, a brownfield in the northern area of the basin. Despite their important role in regional hydrocarbon production, the depositional sequences of the field have been little discussed in academia. In order to contribute to the deposition sequence models of the Upper Cretaceous, the available field seismic was analyzed from the perspective of Sequence Stratigraphy concepts. The results suggest three depositional sequences of short duration (3 - $10 \mathrm{Ma})$, with an imbalance between ups and downs, which contrasts with the assumptions of sequence models. These are distributed in three canyons up to $10 \mathrm{~km}$ wide, 282, 202 and $102 \mathrm{~m}$ thick, respectively, located in the Pre-Campanian, Campanian and Mastrichian transition. The first sequence is formed by four system tracts, with small imbalance between two transgressive events of shorter duration compared to two regressive events, which record the sedimentation of low and transgressive tracts, corresponding to the best candidates for reservoir rocks of the field. The second, younger sequence preserves three events of regression and one of transgression; and the third sequence has similar behavior, but with a longer fall duration. The base level variation pattern is not very harmonic and contrasts with the sine curve adopted for prediction of depositional geometries in passive margin basins and with the models interpreted to the north of the basin, where four sequences were identified. The five recorded peaks of fall appear to be related to the high frequency glacioeustatic fluctuations of the Upper Cretaceous.
\end{abstract}

Keywords: Calumbi Formation; Sequence stratigraphy; Shoreline shift events; Submarine canyons. 


\section{INTRODUÇÃO}

A caracterização sísmica de campos petrolíferos é de grande relevância, pois permite aumentar o nível de conhecimento sobre suas propriedades geológicas. Em campos de produção de petróleo antigos, com estágio de produção em declínio e condicionados à rochas-reservatório pouco espessas ou descontínuas, essa caracterização, por vezes, é inexistente. Nesse contexto, está inserido o Campo de Carapitanga (Figura 1), classificado como um campo de acumulação marginal, que pode se tornar inviável economicamente (Siqueira e Santos, 2008). Atualmente, apenas três poços são produtores (9-CG-2-SE, 7-CG-3D-SE, 7-CG-4D-SE) no campo, com uma vazão total próxima de um $1 \mathrm{~m}^{3}$ por dia. O modelo de acumulação do campo é controlado, essencialmente, por armadilhas estratigráficas (ANP, 2005), e a unidade geológica produtora de óleo e gás é a Formação Calumbi, a qual representa o intervalo de deposição siliciclástica associada à fase drifte da Bacia de Sergipe-Alagoas (Campos Neto et al., 2007), importante alvo de exploração de hidrocarbonetos (Rancan et al., 2009).
Apesar de sua grande importância, as informações geológicas dos reservatórios baseiam-se nos testemunhos de sondagem e em alguns perfis geofísicos, o que deixa em aberto questões pouco discutidas, como, por exemplo, a distribuição do arranjo geométrico de arenitos e folhelhos, bem como o significado paleoambiental da Formação Calumbi no Campo de Carapitanga, debatido normalmente na escala da bacia (e.g., Campos Neto et al., 2007), que pode ser mais bem interpretada a partir da análise sísmica existente. O modelo mais aceito para a deposição sedimentar da formação é de um ambiente transicional entre a plataforma continental e o talude, sob influência de fluxos gravitacionais de massa e correntes de turbidez, dada a semelhança litoestratigráfica verificada entre poços de áreas afastadas a poucas dezenas de quilômetros ao norte do campo, onde há evidências do desenvolvimento de cânions que incidem na plataforma continental, originando depósitos sedimentares influenciados por fluxos gravitacionais de massa (Koutsoukos e Beurlen, 1991; Cainelli, 1992; Feijó, 1994; Ronzê, 1995; Silva, 2007). Em contraste com esse modelo, áreas da Bacia de Sergipe-Alagoas mais ao sul preservam
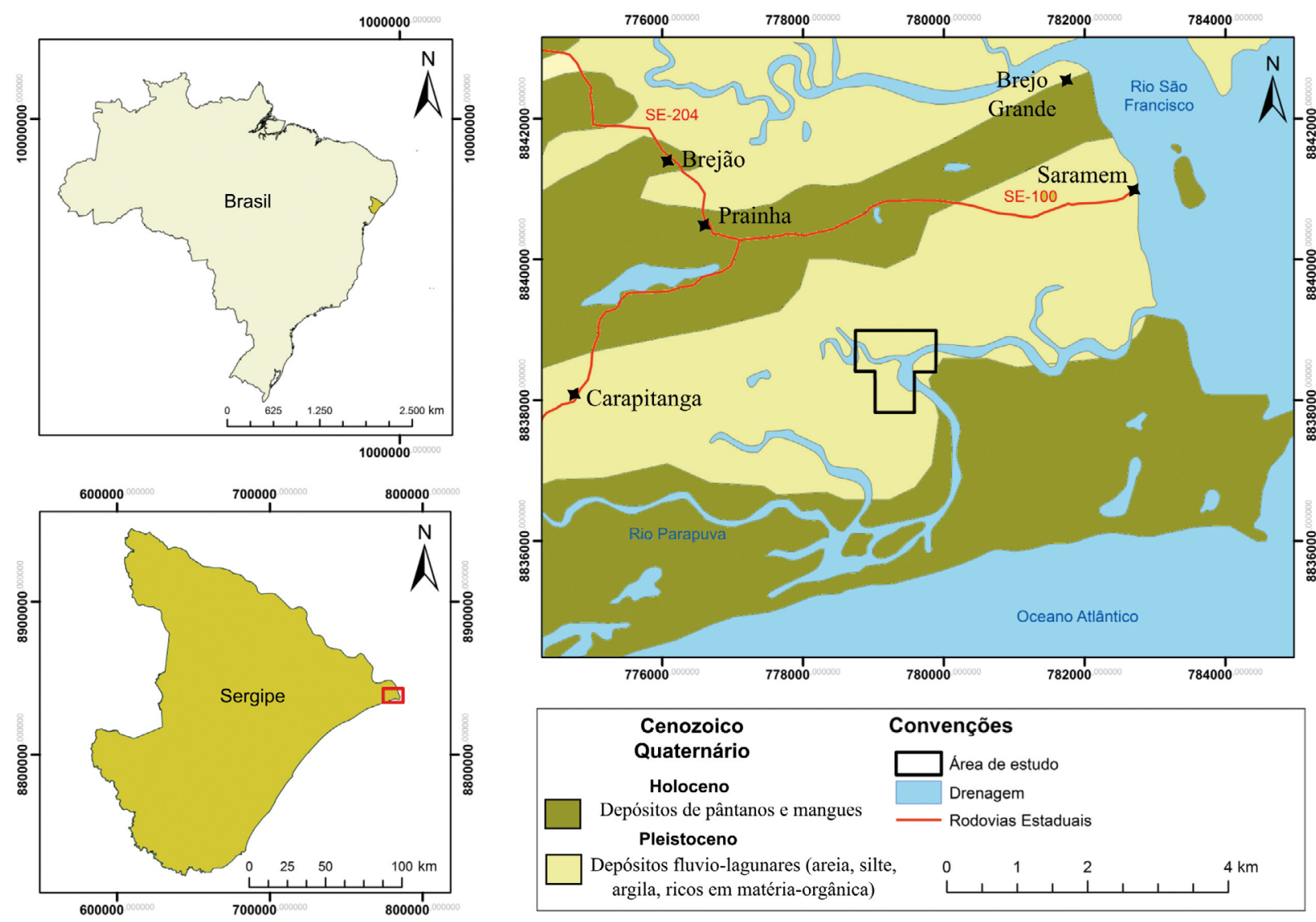

Fonte: extraído e modificado de Teixeira et al. (2014).

Figura 1. Localização do campo de Carapitanga. 
depósitos carbonáticos da Formação Calumbi, cuja gênese está relacionada a ambientes plataformais, sob influência de ondas (Souza-Lima, 2001; Figueiredo, 2014).

Outra questão pouco discutida diz respeito às flutuações do nível de base do mar durante a sedimentação da fase drifte da história do Campo de Carapitanga, entre os estágios Campaniano e Mastrichiano. O primeiro deles pode ser correlacionável à transgressão marinha que teria recoberto áreas continentais ao longo do planeta, atingindo $350 \mathrm{~m}$ acima do nível de base atual, e interpretada como produto de ciclos de terceira ordem (Vail et al., 1977) ou de segunda ordem (Mitchum Jr. e Wagoner, 1991), com picos de subida estimados variando de 10 a $90 \mathrm{~m}$ por milhão de anos (Hancock e Kauffman, 1979). Na escala da Bacia de Sergipe-Alagoas, as evidências de flutuações dessas ordens são notáveis a partir da documentação geométrica apresentada por Cainelli (1992), como uma sequência marcada pelo bypass de formas arenosas em sua porção mais ao norte, e por Campos Neto et al. (2007), que interpretaram três sequências (K-90, K100-110 e K120) e três cânions submarinos.

No sentido de testar a aplicabilidade dos modelos propostos a partir de dados do campo de Carapitanga e de contribuir com novas inferências de geometrias deposicionais, potencialmente controladas por flutuações do nível do mar da ordem de 1 a $10 \mathrm{Ma}$, dentro da Formação Calumbi, o presente trabalho traz resultados de variações do onlap costeiro e da disposição de tratos de sistemas interpretados na seção sísmica do campo. Estes dados podem auxiliar para compreender melhor a distribuição de corpos arenosos dentro do sistema de cânions submarinos de Carapitanga.

\section{CONTEXTO GEOLÓGICO}

A Bacia de Sergipe-Alagoas está situada nos Estados homônimos do Nordeste do Brasil e faz parte de um conjunto de bacias sedimentares formadas a partir da fragmentação da porção oeste do supercontinente Gondwana, que preserva no registro geológico e fóssil evidências da sedimentação ocorrida desde o Neojurássico ao Eocretáceo. Do ponto de vista fisiográfico, a bacia está inserida na margem continental oriental brasileira, tem direção alongada segundo a orientação NE-SW e perfaz uma área total de 44.370 km². $\mathrm{O}$ seu registro sedimentar compreende cinco megassequências: sinéclise, pré-rifte, rifte, transicional e drifte (Jardim de Sá et al., 2008).

O Grupo Piaçabuçu, no qual está inserida a Formação Calumbi, corresponde à fase transicional e drifte, intervalo em que o processo dominante foi o de subsidência térmica, levando ao aprofundamento da bacia e à deposição de espessa sucessão de sedimentos em águas profundas (Figueiredo e
Martins, 1990). A base desse grupo é separada de rochas carbonáticas subjacentes por uma superfície discordante, que marca a mudança de sedimentação carbonática para siliciclástica na bacia, acompanhada de um evento de recuo da linha de costa seguido por intensa erosão da planície costeira e da plataforma exposta. Em consequência da nova elevação do nível de base marinho, no Cretáceo superior, essa plataforma teria sido recoberta, gerando novo espaço para acomodação de sedimentos, dessa vez em um contexto transgressivo, no qual foram preservados, principalmente, folhelhos que compõem a Formação Calumbi (Campos Neto et al., 2007).

\section{Estratigrafia e sedimentação da Formação Calumbi}

A Formação Calumbi tem sido alvo de pesquisas direcionadas para interpretação paleoambiental, principalmente por meio de dados de subsuperfície, visando intervalos de reservatório de óleo e gás (Schaller, 1969; Ponte et al., 1975; Cainelli, 1992; Feijó, 1994; Silva, 2007; Rancan et al., 2009), com poucos trabalhos dedicados a estudos de afloramento (Souza-Lima, 2001; Figueiredo, 2014).

Do ponto de vista estratigráfico, a unidade de estudo tem seu limite inferior definido a partir do reconhecimento da discordância Pré-Piaçabuçu ou Pré-Calumbi (Schaller, 1969), desenvolvida após a queda regional do nível de base, que teria causado a subexposição de uma plataforma carbonática (Formação Cotinguiba) e sua erosão por meio do ajuste do perfil de equilíbrio do sistema fluvial ao longo do Estágio Campaniano.

A modificação paleoambiental, provocada por essa variação do nível de base, teria condicionado a geração de fluxos gravitacionais e de leques submarinos, registrados próximos ao campo de Carapitanga, alvo do presente estudo, na forma de arenitos e folhelhos intercalados (Ponte et al., 1975).

Posteriormente, Cainelli (1992) reconheceu a discordância Pré-Calumbi, interpretada como hiato de exposição subaérea da plataforma carbonática, correspondente à Formação Cotinguiba, e propôs quatro sequências deposicionais para a Formação Calumbi, divididas em:

- Sequência 1: Cretáceo Superior;

- Sequência 2: Paleoceno;

- Sequência 3: Eoceno;

- Sequência 4: Oligoceno/Quaternário.

A Sequência 1 compreende os estágios Campaniano e Maastrichtiano (Figura 2) e teria sido marcada pelo bypass de formas de leito arenosas, interpretadas a partir de clinoformas progradantes com altos ângulos de downlap sobre a base da unidade. A Sequência 2 corresponde à sedimentação durante o Paleoceno, que teria obedecido um padrão de terminação de refletores em onlap ainda em desenvolvimento, 
em que as fácies de plataforma teriam sido formadas predominantemente por arenitos, intercalados localmente com carbonatos na margem. A sedimentação do Eoceno foi precedida por uma discordância bem definida que corta o talude do Paleoceno e a plataforma externa. A sedimentação do Eoceno (Sequência 3) representa um pulso progradacional que empurrou o limite da plataforma para o fundo da bacia e a preencheu por meio de clinoformas de alto ângulo, criadas por cânions associados com a discordância pré-Eoceno. Durante esse tempo, uma plataforma mista clástica-carbonática é estabilizada, com arenitos de plataforma costeira transicionando para carbonatos em direção ao mar ao longo do limite da plataforma. Ao fim do Eoceno, o limite da paleoplataforma encontra-se perto da plataforma atual. Durante o Mioceno, uma grande influência das correntes oceânicas retrabalhou sedimentos trazidos por rios para plataforma e os redistribuiu paralelos à linha de costa de Sergipe, longe do aporte terrígeno, o que condicionou a formação de carbonatos.

Feijó (1994) organizou esses depósitos em três unidades litoestratigráficas pertencentes ao Grupo Piaçabuçu, sendo a Formação Calumbi a unidade da base.

Na região de Nossa Senhora do Socorro, $100 \mathrm{~km}$ ao sul da área de estudo, a unidade é formada por camadas tabulares de até $70 \mathrm{~cm}$ de arenitos quartzosos, com grãos muito bem selecionados, ricos em icnofácies Ophiomorpha nodosa e Thalassinoides, intercalados com espessos depósitos de folhelhos e siltitos laminados (Souza-Lima, 2001). Segundo Souza-Lima (2001), essa associação litológica e de icnofácies é compatível com paleoambientes formados por barras subaquosas ao longo de sistemas marinhos

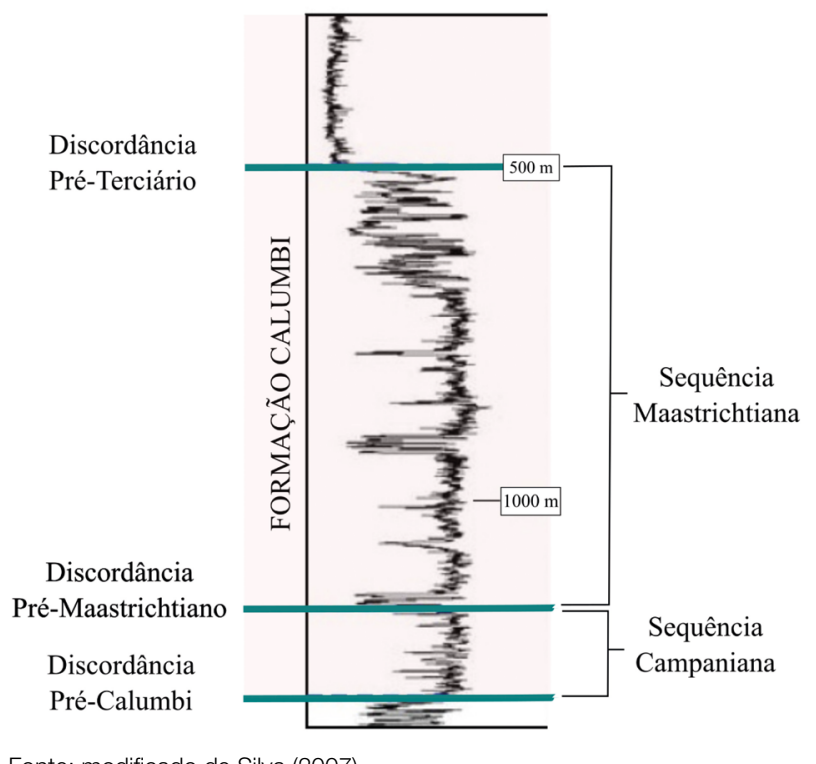

Fonte: modificado de Silva (2007).

Figura 2. Sequências deposicionais da Formação Calumbi a partir de perfis de raios-gama. plataformais rasos, dominados ou não pela ação de ondas de tempo bom ao longo do shoreface. Apesar disso, a variabilidade da distribuição ecológica da associação de icnofácies identificada pode indicar um contexto deposicional alternativo, em águas mais profundas, abaixo do nível de base de ondas de tempestade, provavelmente sob a influência de correntes de turbidez ao longo de canais submarinos, de forma semelhante à interpretação de Cainelli (1992) para a porção norte da bacia.

Segundo Silva (2007), os cânions submarinos ocorrem ao longo de toda a Formação Calumbi. A discordância Pré-Calumbi ou Subformação Calumbi (Campos Neto et al., 2007) é exemplo do primeiro cânion que teria escavado calcilutitos na base da unidade, sendo logo sobreposta pelo complexo de cânions de Brejo Grande, durante o Campaniano, o qual, por sua vez, foi preenchido por arenitos ao longo de formas canalizadas, preservadas em duas fases de sedimentação (Figura 3). Durante a primeira fase, desenvolveu-se a escavação dos cânions com a formação de depósitos de fluxos de detritos. A segunda fase, descrita como fase de bypass, marca o período em que o cânion funcionou como conduto de sedimentos para a parte mais profunda da bacia. Nesse período, teria ocorrido o desenvolvimento de depósitos residuais conglomeráticos, de pequena espessura, relacionados à queda gradual do nível de interação do orbital de onda com o fundo marinho. Na terceira fase, os cânions passam a receber a maior quantidade de sedimentos. Nessa etapa, formaram-se os complexos de canais e folhelhos por meio de processos de escorregamentos. A última fase, definida como cunha progradante, só foi identificada em outra área do complexo de cânions, denominado de Cânion de Aroeira, cuja característica marcante é a presença de refletores em downlap sobre os complexos de canais da terceira fase.

Campos Neto et al. (2007) corroboram essa interpretação na escala da bacia e correlacionam a primeira transgressão pós-discordânica Pré-Calumbi ao máximo nível de base marinho sobre o continente, durante o Eocampaniano, o que teria condicionado o ambiente para deposição siliciclástica pervasiva de folhelhos. À medida que a taxa de aporte sedimentar se tornava maior do que a taxa de variação positiva do nível de base, iniciavam-se progradações arenosas da Formação Marituba na porção rasa e de folhelhos e raros sedimentos arenosos da Formação Calumbi.

Rancan et al. (2009) confirmam a interpretação de fluxos gravitacionais de massa e de correntes de turbidez para a unidade, além da existência de sistemas costeiros distais descritos anteriormente por Souza-Lima (2001). Posteriormente, Figueiredo (2014), ao estudar afloramentos e lâminas de rocha da Formação Calumbi na região de Aracaju, corroborou a interpretação de ambientes plataformais. 


\section{MATERIAIS E MÉTODOS}

Foram utilizados neste trabalho dados de cinco perfis geofísicos de poços com profundidades médias de $1.500 \mathrm{~m}$ (1-CG-1-SE, 9-CG-2-SE, 7-CG-3D-SE, 7-CG-4D-SE e 7-CG-5D-SE) e duas seções sísmicas do campo de Carapitanga. Cada conjunto de dados de poço era composto de informações litológicas de amostras de calha, informações petrofísicas (porosidade e permeabilidade) e perfis geofísicos de poços (raios-gama, potencial espontâneo, neutrão e resistividade). Entre os cinco perfis de poços disponíveis, foi fornecido perfil sônico apenas para o poço 1-CG-01-SE, que foi utilizado para a conversão de tempo de reflexão em profundidade (Kearey et al., 2009). Esses dados foram cedidos pela empresa EPG do Brasil. Os dados das linhas sísmicas do campo petrolífero de Carapitanga e adjacências foram fornecidos pela Agência Nacional do Petróleo (ANP), solicitação número 8791 .

Os métodos utilizados para tratamento e interpretação de dados geofísicos foram adaptados da literatura especializada (e.g., Selley, 2001; Miall, 2000).

Adicionalmente, foi elaborado um sismograma sintético, por meio do perfil sônico e, posteriormente, a transferência das informações dos poços para as linhas sísmicas. Os dados sísmicos foram tratados, objetivando a redução de ruídos e para sua interpretação foi utilizada Técnica de Volume de Amplitudes - TecVa (Bulhões, 1999; Bulhões e Amorim, 2005).

Como forma de interpretar as seções sísmicas, as sismofácies e os padrões de refletores sísmicos, foram consultados os trabalhos de Mitchum Jr. (1977), Galloway (1989), Emery e Myers (1996), Catuneanu (2006), Veeken (2007).

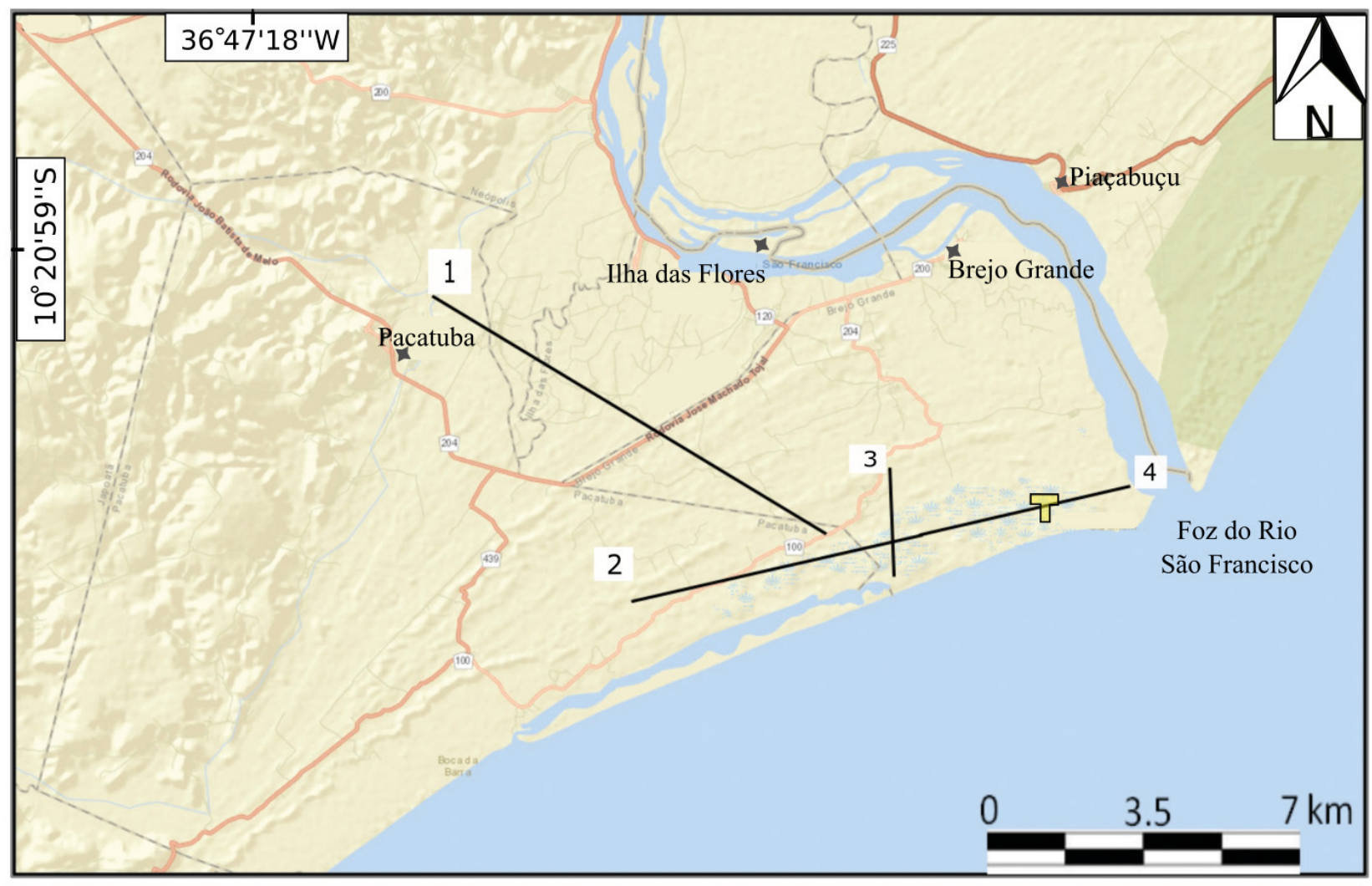

Linha sísmica

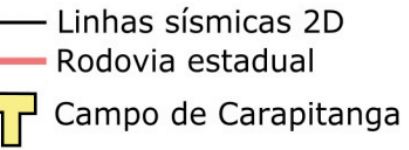

\begin{tabular}{|c|c|}
\hline 1 & 0027_Sergipe_Alagoas_39.0027-1152.mig_fin.1 \\
\hline 2 & 0026_Sergipe_Alagoas_39.0026-0078.mig_fin.3 \\
\hline$J$ & 0026_Sergipe_Alagoas_39.0026-0081.mig_fin.3 \\
\hline 4 & .00 \\
\hline
\end{tabular}

Figura 3. Localização das linhas sísmicas. 
Os dados de perfis geofísicos de poços (de raios-gama, potencial espontâneo, neutrão e resistividade) foram interpretados com base nas propostas de Mitchum Jr. e Wagoner (1991), Veeken (2007) e Keary et al. (2009).

A interpretação da geometria deposicional foi possível por meio da comparação direta entre os resultados da interpretação das linhas sísmicas e as respostas de cada perfil de poço, com dados da literatura especializada para modelos de ambientes sedimentares (Reading, 1996; Bouma, 2000; Posamentier e Walker, 2006; Miall, 2010).

\section{RESULTADOS}

Foram utilizadas duas seções sísmicas, linhas 2-4, que interceptam o campo de Carapitanga, de forma paralela à linha de costa atual da área, a partir da qual foram feitas as interpretações. As demais seções abrangem áreas adjacentes ao campo e têm orientação oblíqua (Figura 3).

Com base na comparação dos dados da linha sísmica 2-4 com os dados do poço 1-CG-1-SE foi possível construir a curva tempo-profundidade (Figura 4), com o auxílio do perfil de raios sônicos, por meio de seu ajuste pelo sismograma sintético.

\section{Perfis de raios-gama e neutrão}

O perfil de raios-gama atravessou mais de $1.500 \mathrm{~m}$ de profundidade, e ao longo do intervalo de tempo 700 a $1.200 \mathrm{~ms}$ registrou poucas variações, sendo duas delas interpretadas como a base e o topo da Fm. Calumbi. Nesse intervalo, notou-se também pouca variação do perfil neutrão, que aumenta de valor na base da unidade. A base foi marcada e definida pela comparação da queda brusca nos valores do perfil de espectrometria gama com os litotipos descritos nos perfis de poços (Figura 4). Valores mais baixos de raios-gama são indicadores de menor argilosidade ao longo do limite inferior da unidade, que, pelo perfil litológico, é marcado pela passagem de folhelhos para arenitos do topo da Fm. Cotinguiba.

\section{Refletores sísmicos e sismofácies}

A análise do conjunto de refletores sísmicos permitiu interpretá-los em seis sismofácies: (Sf1) caótica, (Sf2) segmentada, (Sf3) subparalela, (Sf4) oblíqua, (Sf5) divergente e (Sf6) ondulada (Figura 5).

\section{Sf1 - Sismofácies caótica}

Este padrão ocorre com frequência ao longo do intervalo pertencente à Formação Calumbi. Pode ocorrer associada ao preenchimento de formas canalizadas, sendo sobreposta, em sua maioria, por refletores paralelos. Nas linhas sísmicas, o padrão caótico é caracterizado pela descontinuidade dos refletores e discordâncias, dificultando o seu mapeamento.

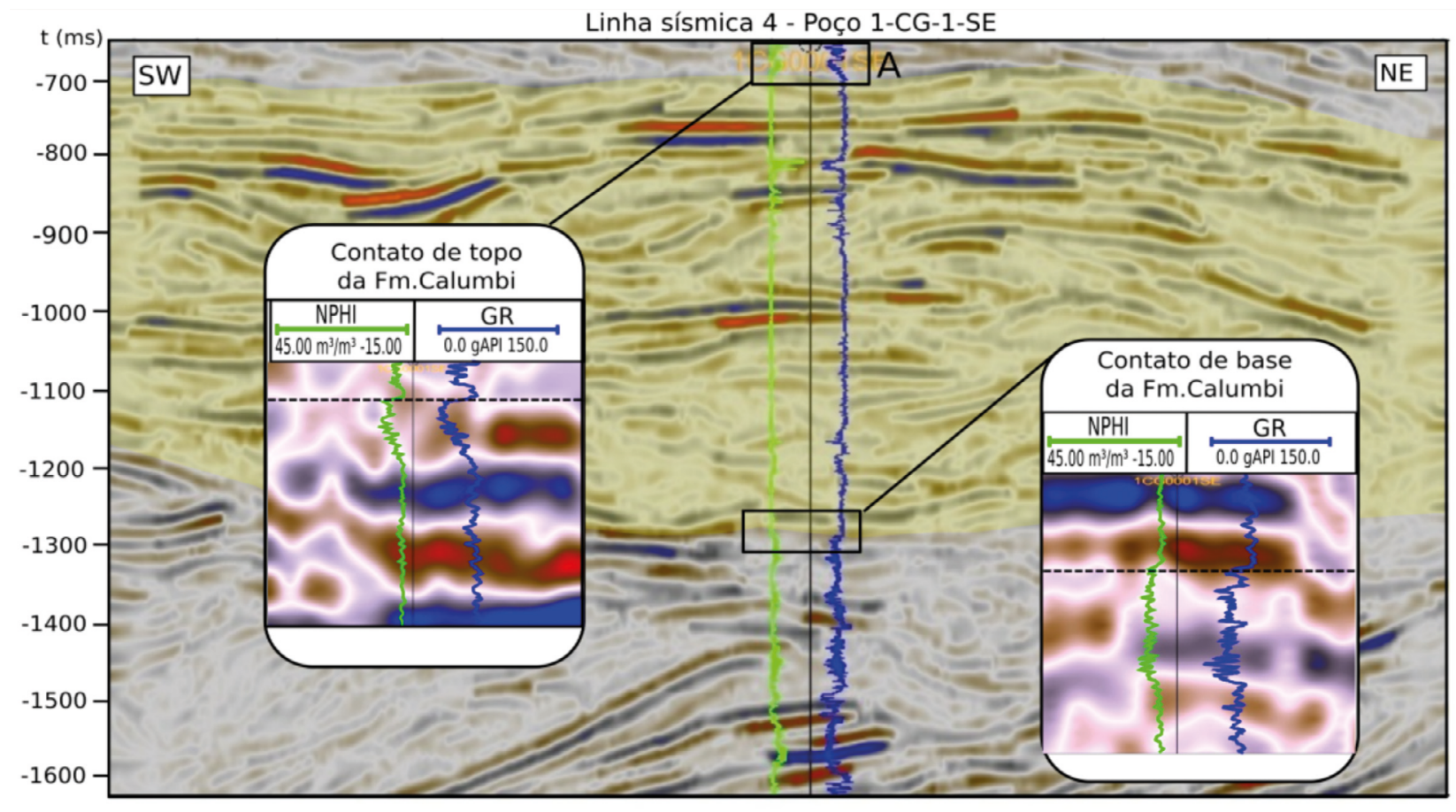

Figura 4. Intervalo em subssuperfície interpretado para a Formação Calumbi no campo de Carapitanga. 
Interpretação

A deposição caótica é característica de depósitos de fluxos gravitacionais ou depósitos de areia retrabalhados de fundo de canal (Haq, 1993). Na base da seção pode indicar a presença de rochas do embasamento, em que a diferença de impedância acústica das camadas é menor.

\section{Sf2 — Sismofácies segmentada}

Esta sismofácies compreende o conjunto de refletores segmentados, comuns na porção superior da seção, próximo ao limite de topo da unidade, no topo do centro de formas canalizadas e sobre a Formação Calumbi. Corresponde a descontinuidades laterais dos refletores regulares (r3) e, raramente, de refletores sigmoidais, principalmente sobre o intervalo em que as formas canalizadas suavizam o mergulho.

\section{Interpretação}

Pode-se atribuir a esses refletores uma origem tectônica, o que corresponderia a superfícies deposicionais associadas às falhas com geração e preservação de altos baixos estruturais.

\section{Sf3 - Sismofácies subparalela}

Esta sismofácies compreende o conjunto de refletores subparalelos, cuja frequência é a maior entre todos na seção, podendo apresentar variações laterais de subparalelos para refletores regulares e hummocky, sendo o primeiro mais comum. Cada subtipo de refletor varia entre si lateralmente e para o topo. Pode ocorrer preenchendo geometrias pouco canalizadas a canalizadas, tendo como terminação padrões em onlap, downlap e em truncamento erosivo. Estes dois últimos tipos de terminação ocorrem em lados opostos de superfícies de base de canal, normalmente na porção basal

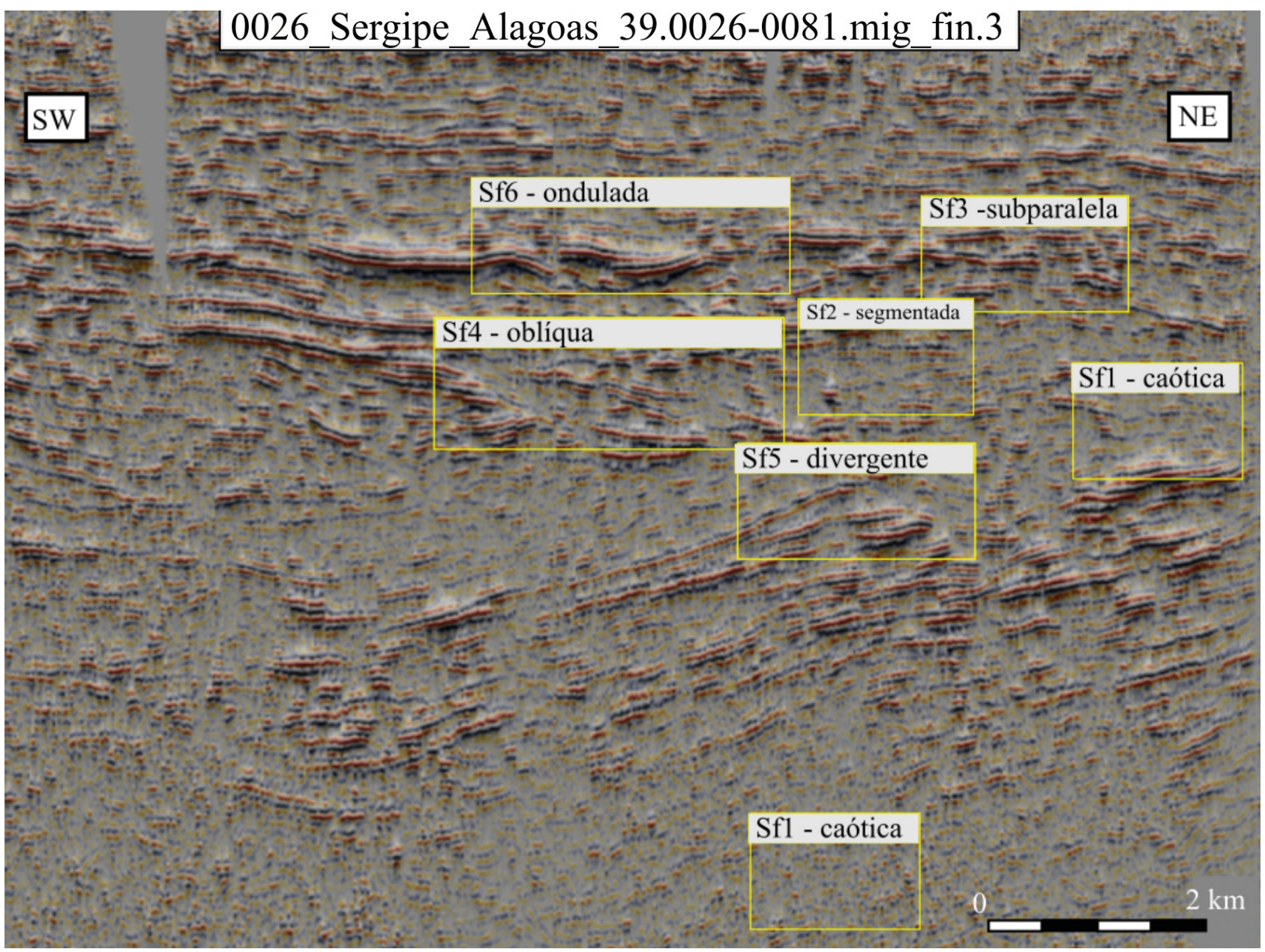

Figura 5. Sismofácies identificadas ao longo da sísmica TecVa que atravessa o campo de Carapitanga. 
e intermediária da seção (Figura 5). Quando ocorrem preenchendo geometrias pouco canalizadas podem permanecer regulares por $5 \mathrm{~km}$ de extensão. Isso é observável na porção superior da seção, em que variam localmente para os lados para refletores ora segmentados, ora tangenciais ou sigmoidais. No topo de cada conjunto desse padrão é possível observar refletores ondulados de maior extensão (r2), que recobrem, ao mesmo tempo, refletores muito ondulados $(\mathrm{r} 1)$ e refletores paralelos $(\mathrm{r} 4)$.

\section{Interpretação}

Este padrão de refletor é o mais comum nas seções e pode ser interpretado como preenchimento regular na parte interna do topo do canal submarino e, principalmente, nas margens, nas quais é mais extenso. No topo pode ser interpretado como produto de agradação deposicional, enquanto nas margens sua origem pode estar relacionada a feições de corte e preenchimento posterior por decantação regular de lama (e.g., Mitchum Jr. et al., 1977; Veeken, 2007) (Figura 5).

\section{Sf4 — Sismofácies oblíqua}

A sismofácies oblíqua compreende conjunto de refletores que podem variar para sigmoidais ou tangenciais (Sangree e Widmier, 1977). Ela é comum na seção e está normalmente limitada nas porções central e superior, em que pode ocorrer como uma transição lateral de refletores paralelos que variam para clinoformas tangenciais ou sigmoidais, associados a terminações em downlap para oeste e para leste, com $1,5 \mathrm{~km}$ de extensão e $500 \mathrm{~m}$ de espessura (Figura 6). No centro da seção podem transicionar para refletores segmentados, além de raramente poder terminar como downlap e offlap ao longo do mesmo refletor. As reflexões oblíquas apresentam mergulho bem marcado na base do pacote, suavizando em direção ao topo. Essas reflexões têm contato basal do tipo downlap sobre o truncamento da fácies sísmica sotoposta. No limite superior têm contato tipo toplap com fácies plano-paralelas sotopostas. Sobrepostas a esses refletores foram mapeadas reflexões subparalelas que apresentam refletores com terminações downlap e toplap que, por vezes, são erodidos pela presença de canais.

\section{Interpretação}

As reflexões foram interpretadas como frentes de séries que deslocam o sistema deposicional em baixo ângulo em relação ao relevo anterior para o fundo da bacia, como progradações. O contato basal do tipo downlap sobre o truncamento da fácies sísmica sigmoidal com a subparalela pode ser a descontinuidade marcante de um limite de sequência (Ls), reconhecida e mapeada no trabalho de
Silva (2007). A arquitetura externa, formada por pouca preservação de terminações de refletores tangenciais na base ou paralelos no topo, pode indicar queda brusca de detritos ao longo de um talude de alta energia de sedimentação (Veeken, 2007).

\section{Sf5 - Sismofácies divergente}

A sismofácies divergente compõe o conjunto de refletores divergentes que ocorrem em menor frequência na seção, normalmente associados ao preenchimento do topo, no centro de refletores ondulados. É comum que esses refletores acompanhem de forma concordante a superfície anterior formada por refletores ondulados, fazendo uma convexidade para o topo da seção, até inflexionar e mergulharem forte para SW (Figura 7).

\section{Interpretação}

A geometria externa dos refletores divergentes é compatível com a migração de barras arenosas que acompanham a mudança de posição do canal, e posterior preservação de feições semelhantes ao dique marginal (Miall, 2000).

\section{Sf6 - Sismofácies ondulada}

A sismofácies ondulada representa o agrupamento de poucos refletores ondulados a muito ondulados, comuns ao longo da seção e que compõem uma variação lateral de refletores regulares com maior ângulo de mergulho e maior extensão em área. Podem atingir até $10 \mathrm{~km}$ de extensão e variar entre 500 e $1.500 \mathrm{~m}$ de continuidade por meio de uma superfície de suave mergulho para SW e NE, até formar alto ângulo de mergulho, de aproximadamente $15^{\circ}$ no centro, no qual preservam forma geométrica externa bem canalizada, sendo recobertos por refletores regulares. É comum a sobreposição destes por sismofácies oblíquas. A terminação lateral de refletores pode ser observada na base da seção sísmica, na qual é marcada pelo padrão de onlap para SW e NE, e em sua porção intermediária, em que é dominada pelo mesmo padrão, somente para SW. Para o topo da seção, a terminação de refletores não é clara, pois ultrapassa o limite da seção observável; apesar disso, no centro da seção é possível observar, sutilmente, padrões em offlap.

\section{Interpretação}

A geometria externa dos refletores ondulados é compatível com superfícies de base de canais submarinos, cuja incisão pode até atingir até $1,5 \mathrm{~km}$ de profundidade. O preenchimento que recobre a superfície basal, interpretada como erosiva, poderia representar um sistema de canais 

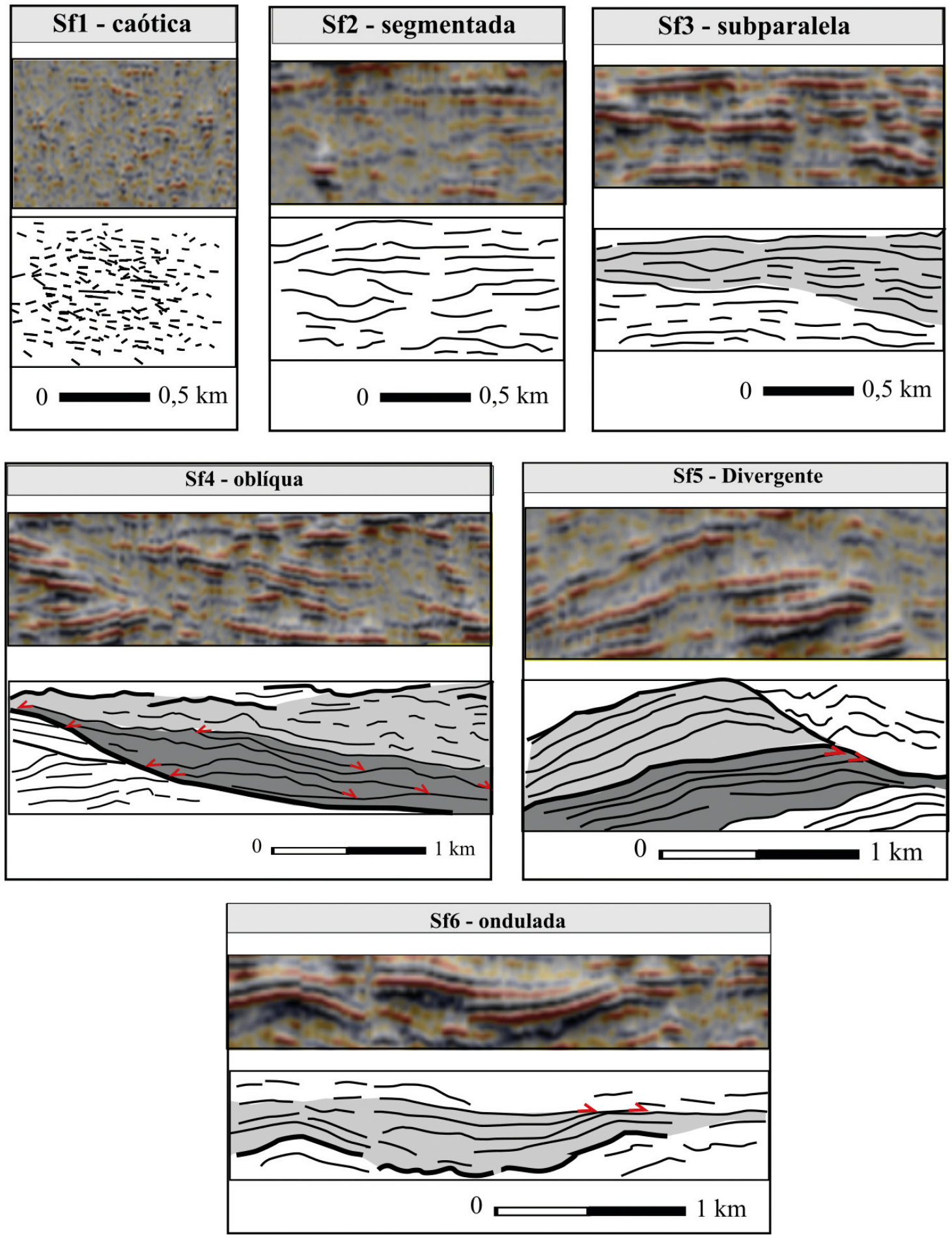

Figura 6. Resumo das sismofácies interpretadas e principais geometrias associadas a suas terminações. (Sf4) Oblíqua - Notar formas inclinadas com padrão de preenchimento agradacional para retrogradacional até a última terminação em onlap na extrema esquerda (cinza escuro). Ao centro aparece a primeira terminação em offlap, indicando possível progradação e expansão do fluxo dado pelos refletores segmentados a pouco caóticos (cinza claro). (Sf5) Divergente - Migração lateral de barras arenosas para SW (esquerda - cinza escuro) com construção de dique marginal para o topo (cinza claro) e preenchimento de canal à direita por refletores segmentados interpretados como escorregamentos (branco). (Sf6) Ondulada - Preservação de base de canal, interpretado como vale inciso de até 1,5 km de largura, preenchido por formas de leito progradacionais da direita para esquerda. Notar padrão segmentado no centro que lateralmente muda para subparalelo. 
submarinos preenchidos, com até $10 \mathrm{~km}$ de extensão. A diferença entre padrões de terminação de refletores em onlap na base para terminação em offlap no topo sugere que houve duas formas de preenchimento, uma marcada pela subida gradual do nível de base à medida que o canal era afogado e outra no topo, relacionada a pequena variação do nível de base, seguida por quedas pouco frequentes (Catuneanu, 2006).

\section{Superfícies limitantes}

A descrição e a interpretação das superfícies limitantes foram adaptadas da proposta de Galloway (1989) e divididas em: superfície de escavação de canal (Sc), superfície regressiva $(\mathrm{Sr})$, superfície regressiva máxima (Srm), superfície transgressiva (St), superfície transgressiva máxima (Stm) e superfície basal de regressão forçada (Figura 7).

\section{Superfície de escavação de canal (Sc)}

Esta superfície tem a maior extensão em área na bacia, podendo atingir $10 \mathrm{~km}$; apesar disso, é a menos frequente no tempo, tendo sido identificada dentro da Fm. Calumbi em três intervalos (Figura 8). É possível interpretá-la a partir de refletores ondulados como produto do rebaixamento regional do nível de base, seguido por erosão dos estratos anteriores e preservação de fundos de vale incisos. A distribuição dessa geometria associada ao recobrimento por sismofácies caóticas ou segmentadas no centro, que se tornam onduladas e subparalelas para os lados, sugere que a deposição sedimentar teria ocorrido predominantemente por fluxos de gravidade (escorregamentos) ou por correntes de turbidez. Nota-se, a partir da distribuição dessas formas geométricas, que houve mudança lateral progressiva do canal de NE para SW desde a base até o topo da unidade.

\section{Superfície regressiva (Sr)}

A superfície regressiva pode ocorrer na forma de recuos pequenos do nível de base, com variação espacial na bacia de até $1 \mathrm{~km}$ da posição do onlap anterior (Figura 9). Foram identificadas apenas em duas posições das seções estudadas. Interpreta-se que essa superfície esteja relacionada às flutuações negativas do nível de base dentro da escala de tempo da construção do sistema deposicional

\section{Superfície regressiva máxima (Srm)}

Esta superfície ocorre uma vez na seção e pode ser interpretada como a maior queda do nível de base marinho, com ampla exposição regional e erosão da plataforma anterior, por, pelo menos, 6 km de extensão de SW para NE. Sobre ela desenvolvem-se sistemas deposicionais relacionados ao menor de espaço de acomodação, provavelmente no contexto de mar baixo. Dessa forma, é possível inferir que se trata de uma superfície relacionada ao limite de sequência do tipo I (Ls).

\section{Superfície transgressiva (St)}

A superfície transgressiva é frequente e foi identificada quatro vezes no intervalo da unidade (Fm. Calumbi). Corresponde ao

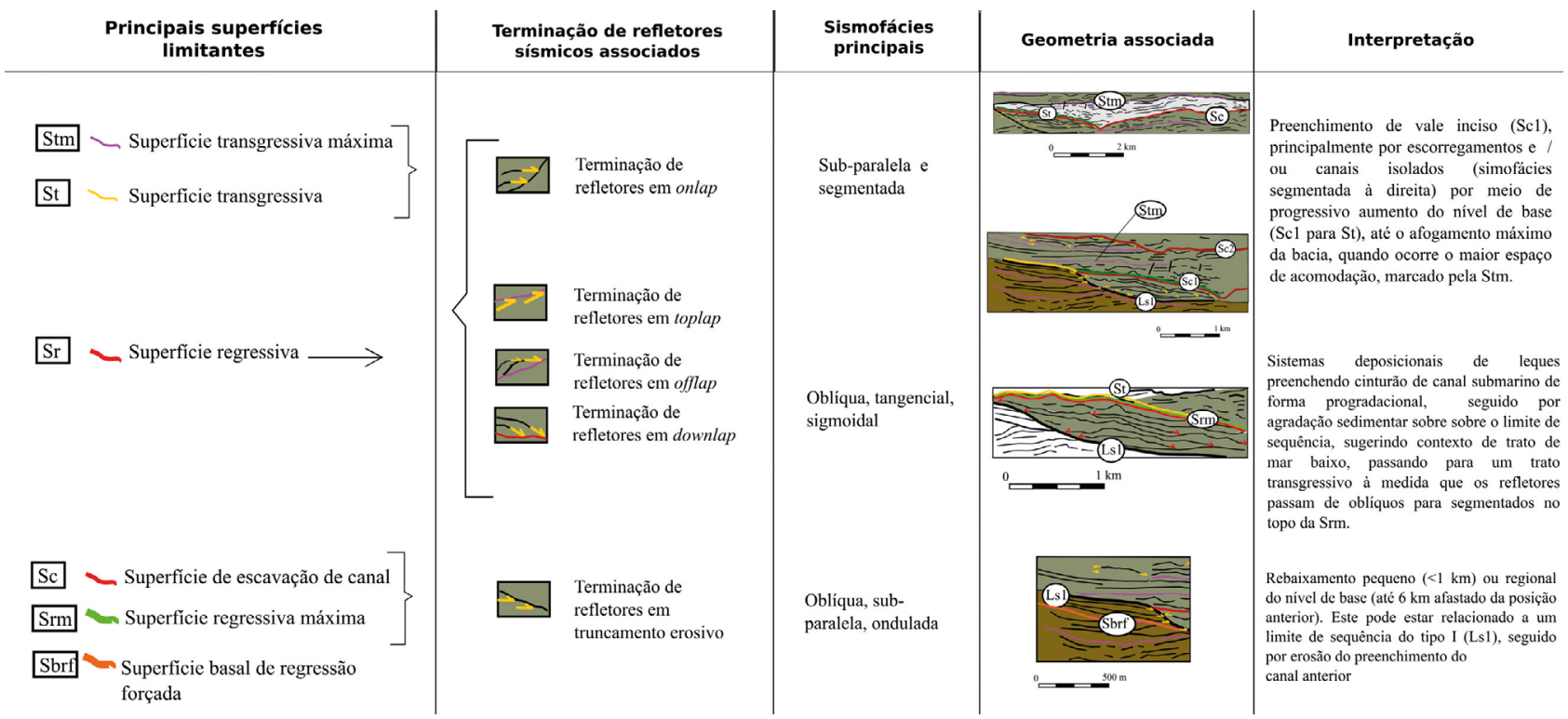

Figura 7. Principais superfícies limitantes, terminações de refletores e padrões geométricos interpretados nas seções sísmicas. 
recobrimento de sismofácies segmentadas e subparalelas, logo acima do Ls ou de superfícies de escavação de canal. Foi descrita como uma superfície de refletor subparalelo a pouco ondulado de extensão equivalente às superfícies de escavação de canal e do Ls, podendo atingir até $10 \mathrm{~km}$. É possível interpretá-la como limite de base de sistemas deposicionais de trato de mar alto e de topo de sistemas de trato transgressivo (Catuneanu, 2006), que coincide com o desconfinamento regional do canal (Figura 9A).

\section{Superfície transgressiva máxima (Stm)}

Esta superfície foi passível de identificação uma única vez, ao longo do intervalo médio das seções, em que é possível notar que é recoberta por uma superfície de escavação de canal e por sucessões progradacionais abaixo. Interpreta-se
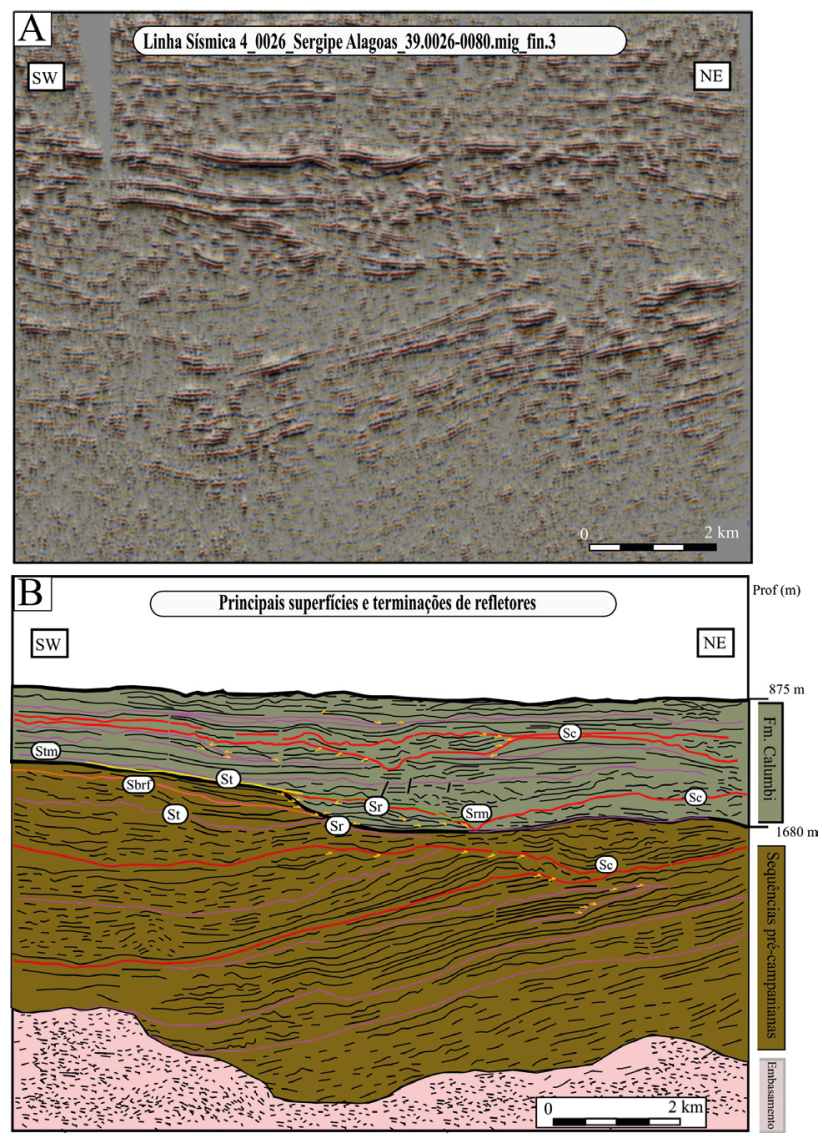

Figura 8. (A) Linha sísmica 4 (TecVa); (B) Interpretação sísmica para a Formação Calumbi e Sequências préCampanianas no Campo de Carapitanga. Notar três mudanças laterais sucessivas de posição de vales incisos por meio de superfícies canalizadas (Sc) de NE para SW (linhas vermelhas) preenchidos por fluxos gravitacionais. Para o topo ocorrem superfícies transgressivas (St), marcando a subida gradual do nível de base até seu máximo (Stm), onde ocorre o segundo canal. que ao longo deste intervalo cronoestratigráfico houve a primeira maior subida do nível de base ao longo da deposição da Fm. Calumbi.

\section{Superfície basal de regressão forçada (Sbrf)}

A superfície basal de regressão forçada foi identificada três vezes ao $\mathrm{SW}$ ao longo do intervalo da seção, duas vezes dentro da Formação Calumbi e uma vez abaixo da discordância Pré-Calumbi. Apresenta extensão lateral que varia de 3 a $4,5 \mathrm{~km}$, com mergulho suave no sentido do fundo da bacia. Sobre ela ocorrem refletores com terminações em onlap e offlap, o que sugere progradação durante a queda. Cada ocorrência da superfície foi interpretada como a base do trato de sistemas de estágio de queda (TSEQ), de forma semelhante à interpretação de Plint e Nummedal (2000). $\mathrm{Na}$ seção estudada essas superfícies ocorrem antes da superfície do Ls e marcam a base de duas regressões marinhas enquanto a queda do nível do mar ainda era moderada (Figuras 9A e 9B).

\section{Arquitetura deposicional próxima ao Campo de Carapitanga}

Ao longo da seção sísmica foi possível notar a repetição de uma organização geométrica que alterna preservação de formas sigmoidais de grande escala arquitetural com formas canalizadas. Ao todo, foram interpretadas três grandes formas progradacionais definidas por sistemas deposicionais com nível de base muito baixo, definidos logo acima do Ls e três cânions, cujos talvegues se deslocam, lateralmente, do fundo da bacia (NE) para o continente ao $\mathrm{SW}$, sendo preenchidos por padrões progressivamente agradacionais e retrogradacionais, formando três sequências com espessuras que diminuem para o topo (Figura 9A). Cada uma delas compreende um trato: um trato de sistema de mar baixo (TSMB), um de trato de sistema transgressivo (TST1), um trato de sistema de mar alto (TSMA) e um trato de sistema de estágio de queda de nível de base (TSEQ), preservados desequilibrados ao longo de cada sequência (Figura 9B).

\section{Transição: trato de sistema de estágio de queda - discordância Pré-Calumbi}

Da base para o topo é possível notar três superfícies regressivas sucessivas (linhas laranja, preta e verde - Figuras 9A e 9B). A primeira delas foi interpretada como superfície basal de regressão forçada e a segunda, como Ls, respectivamente, a base e o topo do preenchimento interno, em que estão preservados três refletores em onlap, offlap e onlap, respectivamente, com terminação de refletores em truncamento erosivo (setas azuis) logo abaixo do Ls. A próxima 
posição do refletor em onlap ocorre $3 \mathrm{~km}$ para NE em direção ao fundo da bacia, representado pelo primeiro onlap sobre o Ls. O distanciamento entre as posições 3 e 4 do onlap (setas amarelas - Figura 9B) permite interpretar que os primeiros sistemas deposicionais contemporâneos compunham um trato de sistemas de estágio de queda (TSEQ), depositado
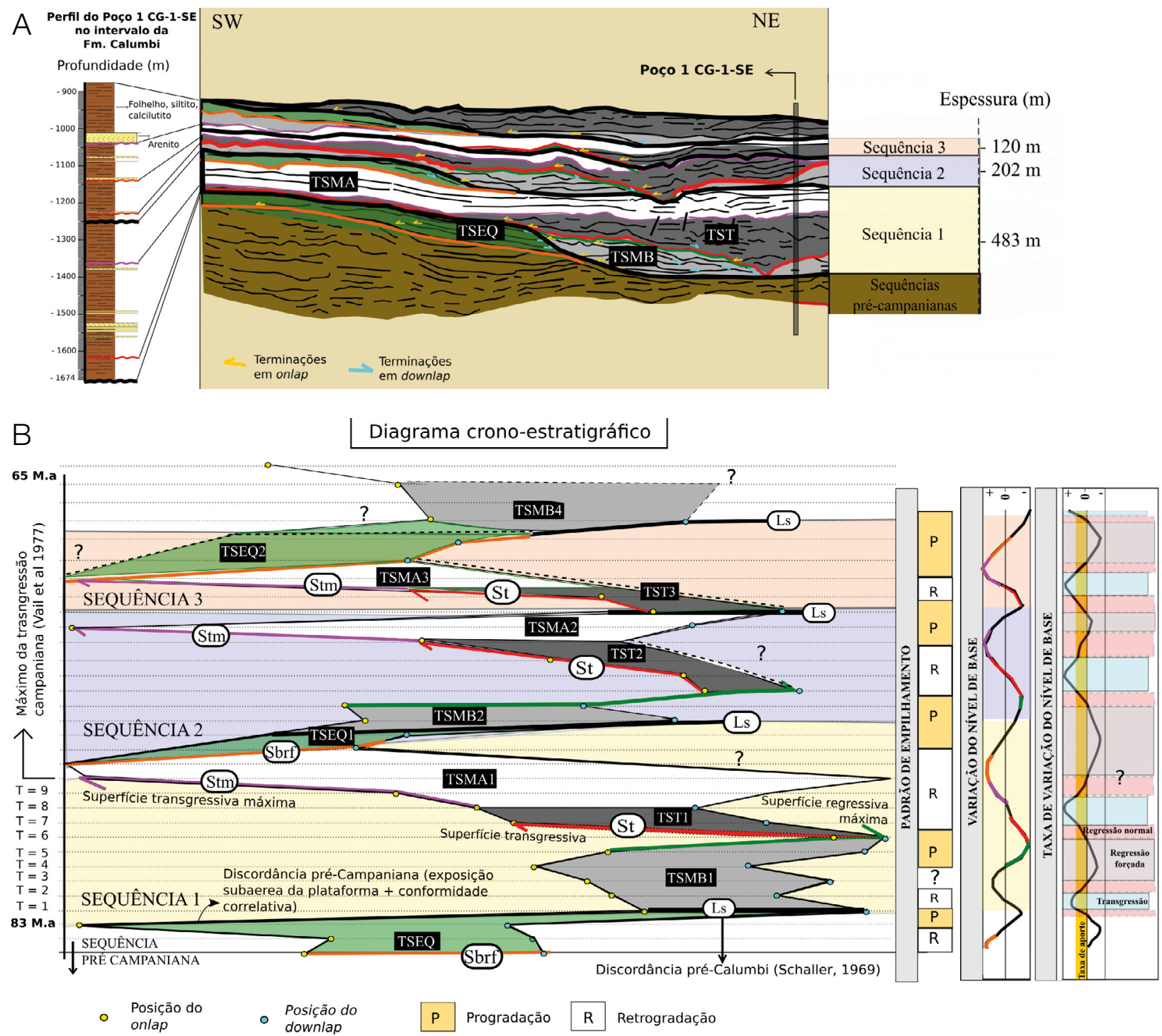

Figura 9. (A) Três sequências interpretadas para a Formação Calumbi e os respectivos tratos de sistemas deposicionais. À esquerda, perfil litoestratigráfico do poço 1 CG-1-SE. Superfícies principais: Sbrf (linha laranja) - superfície basal de regressão forçada, Ls (linha preta) - limite de sequência, Srm (linha verde) - superfície regressiva máxima, St (linha vermelha) - superfície transgressiva, Stm (linha rosa) - superfície transgressiva máxima. Tratos principais: trato de sistemas de estágio de queda - TSEQ (verde), trato de sistema de mar baixo - TSMB (cinza claro), trato de sistema transgressivo - TST1 (cinza escuro), trato de sistema de mar alto - TSMA (branco). (B) Diagrama crono-estratigráfico, mostrando a variação do nível de base e da taxa de variação do nível de base, interpretado a partir do deslocamento dos refletores em onlap e downlap ao longo da deposição sedimentar da Fm. Calumbi (interpretação adotou taxas de aporte sedimentar semelhantes à proposta de Catuneanu, 2006). Da base para o topo da sequência destacam-se cinco superfícies: Sbrf - superfície de base de regressão forçada (linha laranja), LS - limite de sequência (linha preta grossa contínua), Srm - superfície regressiva máxima (linha verde), St - superfície transgressiva (linha vermelha), Stm superfície transgressiva máxima (linha roxa). TSEQ - trato de sistemas de estágio de queda, TSMB - trato de sistemas de mar baixo, TST1 - trato de sistemas transgressivo, TSMA - trato de sistemas de mar alto. Linhas grossas tracejadas representam falta de informações. 
durante o início de queda lenta do primeiro evento de regressão marinha campaniana, que posteriormente evolui para uma queda acentuada durante a formação da superfície seguinte, o Ls.

O Ls marca o topo do TSEQ e foi interpretado a partir da descrição de um refletor sísmico muito ondulado, de extensão regional, com deslocamento horizontal de terminações em onlap muito distantes abaixo e acima dele, com mergulho suave (4 km ao SW) a moderado para NE, que é sobreposto por sismofácies ondulada, segmentada, caótica e oblíqua (Figura 9A). Quando sobreposto por refletores ondulados, o contato é pontual, o que sugere a presença de um vale inciso/cânion. Quando ocorre abaixo de refletores oblíquos com terminação em downlap, pode ser inferida queda sucessiva do nível de base, o que faz desta superfície a conformidade correlativa da área de plataforma exposta ao SW.

\section{Sequência 1 (Campaniana) - trato de sistema de mar baixo}

A Sequência 1 inicia-se com a preservação dos primeiros cinco recobrimentos de clinoformas com terminação em onlap e downlap sobre o Ls (preenchimento cinza claro Figura 9A). Estas clinoformas denotam progradação lenta até o momento de queda mais rápida, quando se forma o Ls, por meio de exposição completa do trato de sistemas anterior.

O padrão de terminação com sucessivos refletores em downlap, ora mais proximais ora mais distais e dos três primeiros refletores em onlap se aproximando do continente, sugere que, apesar de ser possível interpretar um rebaixamento regional do nível de base, marcado pela superfície regressiva, este ocorreu de forma equilibrada com o aporte sedimentar e a subsidência, que permitiam que houvesse retrogradações e progradações intercaladas dentro mesmo tempo de nível oceânico baixo (Figura 9B). Os Ls, como base neste padrão geométrico sigmoidal e de topo recoberto por uma superfície regressiva máxima, sugerem a presença de um TSMB (Figura 9B).

\section{Sequência 1 - trato de sistema transgressivo}

Com relação ao preenchimento interno é possível notar um refletor muito ondulado, interpretado como uma incisão fluvial com cerca de $4 \mathrm{~km}$ de largura (superfície canalizada - Sc1), que, por sua vez, é recoberta por sismofácies segmentadas e caóticas. Essa forma canalizada preenchida é sobreposta por um refletor contínuo de extensão regional, que, para SW, recobre diretamente o limite de sequência do tipo I, tendo sido interpretada como superfície transgressiva 1 (St1 - linha vermelha) da bacia, que recobre os dois tratos anteriores, e é, por sua vez, a base do TST1.

Esta superfície basal é recoberta por três refletores em onlap associados a sismofácies segmentadas e paralelas.
O progressivo deslocamento desse padrão de terminação para SW até sua superfície basal (transgressiva) praticamente coincide com a superfície seguinte de topo, interpretada como a presença de uma superfície transgressiva máxima (Stm). A área (cinza escuro - Figuras 9A e 9B) representaria o primeiro intervalo de subida do nível de base durante o tempo de deposição da Fm. Calumbi, que teria deslocado a linha de costa de mais de $2 \mathrm{~km}$ costa afora, próxima ao fundo do cânion 1 para uma posição $250 \mathrm{~m}$ acima.

\section{Sequência 1 — trato de sistema de mar alto}

Acima do trato transgressivo é possível notar amplo desconfinamento das formas de grande escala da bacia por meio da mudança no padrão de sismofácies majoritariamente segmentada com terminações em onlap do trato anterior para refletores subparalelos e paralelos de até $2 \mathrm{~km}$ de continuidade, sob as quais está preservada uma superfície transgressiva máxima ( $\mathrm{Stm}$ ), que marca a base do TSMA1.

A espessura de rocha preservada ao longo deste trato é menor do que a do trato anterior, podendo chegar a $201 \mathrm{~m}$, o que pode indicar menor taxa de sedimentação durante $o$ final da subida, sendo essa dominada por folhelhos, siltitos e calcilutitos (Figura 10). O limite de topo é marcado pela segunda aparição da superfície basal de regressão forçada (Figuras 9A e 9B).

\section{Transição: Sequência 1 - Sequência 2}

A transição entre as Sequências 1 e 2 é marcada pela segunda queda regional do nível do mar, interpretada a partir da preservação dos refletores em downlap que preenchem sismofácies inclinadas sobre a superfície basal de regressão forçada e a aparição de novos refletores em onlap e downlap (Figura 10). O preenchimento desta forma geométrica (em verde - Figura 9A) anterior ao segundo limite de sequência representa o trato de estágio de queda, que aparece pela segunda vez na seção sísmica e pela primeira vez na Formação Calumbi, e encerra a sequência deposicional 1.

\section{Transição: Sequência 2 - Sequência 3}

A transição entre as Sequências 2 e 3 foi interpretada a partir do recobrimento de uma nova superfície regressiva não muito acentuada, que define o limite de sequência, sobre a qual estão dispostas terminações de refletores em onlap, muito deslocados para NE, em relação à linha de costa da Sequência 2, dada pela superfície transgressiva máxima. Apesar disso não há aparente desenvolvimento do TSMB, sendo o limite de sequência logo recoberto pelo preenchimento do trato transgressivo, bem assinalado por um novo 
deslocamento para SW da linha de costa, em um intervalo no qual o espaço é superior ao aporte sedimentar (Figura 9B). Isso sugere a presença de um limite de sequência do tipo II, em que o aporte ganha da taxa de subida do nível de base (Figura 10).

\section{DISCUSSÃO}

\section{Sedimentação da Formação Calumbi na Bacia Sergipe-Alagoas}

Os estágios de sedimentação Campaniano e Mastrichiano estão bem documentados e preservam variabilidade deposicional ao longo dos perfis litoestratigráficos da Formação Calumbi na Bacia de Sergipe-Alagoas (Souza-Lima, 2001; Silva, 2007). Ao longo do Campaniano estão preservados depósitos sedimentares correspondentes a ambientes plataformais na região sul da bacia, ao oeste da cidade de Aracaju, onde barras arenosas ricas em icnofácies do gênero Thalassinoides teriam sido formadas sob influência de ondas, intercaladas com pelitos laminados, formados por decantação de argila em ambientes de shoreface e offshore (Souza-Lima, 2001). Apesar disso, a unidade é pobre em afloramentos que permitam extrair informações sobre a arquitetura deposicional, com raras exceções como é o caso da pedreira abandonada próxima à região de Nossa Senhora do Socorro (SE), onde também foram descritos ambientes plataformais sob influência de ondas (Figueiredo, 2014). $\mathrm{Na}$ região norte da bacia, contudo, as informações sobre preenchimento deposicional têm sido obtidas a partir de dados de subsuperfície, com o auxílio de ferramentas sísmicas e de poços exploratórios e produtores (Rancan et al., 2009), cujos modelos de sedimentação apontam para um ambiente distinto daquele do sul, mais sujeito à incisão de cânions submarinos e escorregamentos de talude para planície abissal (Cainelli, 1992).
Próximo à foz do Rio São Francisco, o campo de Carapitanga preserva em subsuperfície rochas da Formação Calumbi, cujo reservatório de óleo e gás está atualmente em declínio e pode ser inviabilizado em função de sua baixa produção (Siqueira e Santos, 2008). Isso se deve, em parte, a pouca informação sobre a arquitetura dos depósitos arenosos que compõem o reservatório, que é condicionado por armadilhas estratigráficas (ANP, 2005). Os novos dados geométricos do preenchimento interno de sismofácies e superfícies no Campo de Carapitanga podem contribuir para amplificar a visão sobre o reservatório.

A interpretação de clinoformas sugere a presença de três sequências deposicionais com tratos de sistemas incompletos e ampla deposição de pelitos, com raras ocorrências de camadas arenosas, compondo uma geometria compatível com três incisões sucessivas da plataforma ao longo da foz do atual Rio São Francisco (Figura 10), de forma semelhante a sistemas deposicionais relacionados a leques submarinos, escorregamentos de borda de vales incisos e sistemas de canais submarinos. Essas informações são compatíveis com trabalhos realizados poucos quilômetros ao norte (e.g., Cainelli, 1992; Ronzê, 1995) e que foram relacionados a eventos de transgressão e regressão entre o Campaniano e o Mastrichiano da Bacia Sergipe-Alagoas (Silva, 2007).

\section{Cânion - Sequência 1 (483 m)}

O cânion 1 compreende maior espessura, podendo atingir $282 \mathrm{~m}$ no talvegue e aproximadamente $10 \mathrm{~km}$ de extensão lateral. É preenchido por sistemas deposicionais que passam de um contexto de queda máxima do nível do mar, progressivamente, para subida lenta, em que é notável a mudança gradual da geração de espaço de acomodação, que dentro da área do canal teria passado de formas amalgamadas no centro e na base, representada pelos refletores caóticos e segmentados, para formas menos canalizadas e desconfinadas para as margens onde os refletores são mais contínuos (Figuras 9A e 10). Esse padrão sugere a passagem de formas

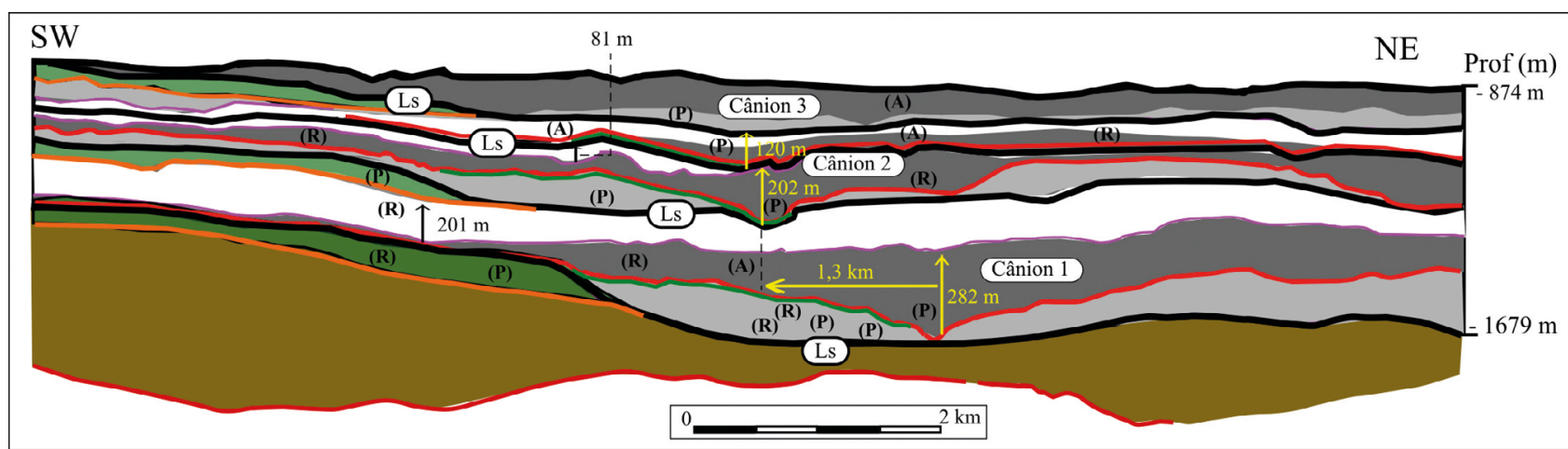

Figura 10. Modelo geométrico de preenchimento sedimentar e evolução de cânions ao longo da linha 4 no Campo de Carapitanga. Notar diminuição sucessivos deslocamentos do cânion 1 para o cânion 3 para SW, assim como aumento paulatino da razão largura/profundidade. 
progradacionais, agradacionais para retrogradacionais, conforme o espaço de acomodação aumentava entre a St1 e a superfície transgressiva máxima ( $\mathrm{Stm}$ - linha roxa).

Tal organização de sismofácies é compatível com a preservação litoestratigráfica de 8 camadas arenosas que variam de 1 até $5 \mathrm{~m}$ de espessura no poço e poderiam corresponder a escorregamentos do talude (Figura 9A).

\section{Cânion - Sequência 2 (202 m)}

$\mathrm{O}$ segundo cânion mapeado tem aproximadamente $3 \mathrm{~km}$ de largura e espessura de $202 \mathrm{~m}$, e seu preenchimento é marcado pela presença de refletores caóticos no centro a, por vezes, pouco ondulados e contínuos nas margens, onde apresentam terminações em onlap. Logo em seguida ao preenchimento da superfície Sc2 (linha vermelha) foi mapeada a última escavação identificada nos limites inferidos para a Formação Calumbi. O paleocanal principal, cerca de $3 \mathrm{~km}$, possui largura maior que os demais.

Diferentemente do cânion anterior, esse canal preserva ao longo do poço estudado apenas uma camada arenosa de cerca de $1 \mathrm{~m}$ de espessura, o que pode indicar que o perfil litoestratigráfico atingiu uma área marginal do cânion, onde a sedimentação arenosa era menor, corroborada pela geometria do trato transgressivo, que representa praticamente a espessura total do cânion na parte central (Figura 10).

\section{Cânion - Sequência 3 (120 m)}

O cânion da sequência 3 é o menor dentre todas, podendo atingir $120 \mathrm{~m}$ de espessura e direção similar a escavação do cânion anterior. O menor deslocamento do onlap costeiro confirma a diminuição do aprofundamento do canal dentre as sequências interpretadas (Figura 10).

Ao longo do perfil litoestratigráfico foram identificadas duas camadas com espessura individual de até $1 \mathrm{~m}$ de arenito, sugerindo diminuição da frequência de escorregamentos à medida que a inclinação das margens dos cânions se tornava menos acentuada.

A distribuição irregular de cânions observada na sísmica (Figura 10) poderia ser explicada pela migração da posição de depocentros, de forma semelhante àquela descrita para os mesmos estágios (Campaniano-Mastrichiano) de sedimentação na porção norte da Bacia de Santos, onde foram interpretadas de três a quatro sequências, relacionadas a rebaixamentos sucessivos com ciclos de 3 Ma de duração (Assine et al., 2008; Garcia et al., 2019).

\section{Oscilações da linha de costa no Campo de Carapitanga}

As três sequências deposicionais reconhecidas entre o intervalo de - 1679 e - 874 m no Campo de Carapitanga diferem um pouco do modelo ao norte, em que foram interpretadas quatro sequências (Cainelli, 1992), e muito da sedimentação interpretada ao sul, na qual predominavam ambientes plataformais (Souza-Lima, 2001). Mesmo assim, mostrou-se bastante coerente com o modelo regional interpretado por Campos Neto et al. (2007).

A Sequência 1 é marcada pelo rebaixamento regional do nível de base, gerado a partir de um primeiro evento de regressão forçada que expõe toda a área da bacia (Figura 9B), permitindo o desenvolvimento de leques submarinos bem marcados por formas progradacionais na base da seção, provavelmente correspondendo à discordância Pré-Calumbi (Silva, 2007; Campos Neto et al., 2007). Essa sequência é bem delimitada por duas quedas sucessivas marcadas por Ls recobrindo o trato de sistemas do estágio de queda. Sobre ele ocorre exposição subaérea ao longo de $4 \mathrm{~km}$ de extensão, que marca a base do trato de mar baixo (Figura 9A). Ao longo dessa sequência estão preservados, de forma desequilibrada, dois eventos de regressão forçada, duas regressões normais e duas transgressões marinhas, sendo esta última menos frequente no tempo, porém mais expressiva em extensão lateral do que o vale inciso. Este ocorre durante o desenvolvimento de canais submarinos e extravasamento regional de canais à medida que o espaço de acomodação aumentava no intervalo que separa a Fm. Calumbi de sequências pré-campanianas.

A Sequência 2 tem menor espessura e compreende um intervalo dominado por regressões, duas normais, dois intervalos de regressão forçada de curta duração e apenas um evento transgressivo. A primeira regressão normal ocorre ao longo do intervalo de subida lenta, logo após a superfície de máxima regressão, e a segunda ocorre durante a descida do nível de base, logo após o intervalo de máxima transgressão, em que se desenvolveram formas progradacionais em contexto de mar alto ou de margem de plataforma. A regressão forçada ocorre ao longo de um intervalo muito condensado de tempo, comparado com aquela interpretada para sequência anterior, logo após o limite de sequência durante o desenvolvimento do segundo trato de mar baixo (Figura 9B).

A Sequência 3 é a menor em espessura e preserva de forma pouco precisa três tratos de sistema que refletem uma queda moderada do nível de base, porém sem preservação dos depósitos de mar baixo.

Essa configuração difere um pouco do modelo de Cainelli (1992), o qual propõe quatro sequências para a Formação Calumbi, situadas mais ao norte. Ainda segundo Cainelli (1992), formas em onlap só ocorreriam a partir da Sequência 2, o que não foi corroborado. No Campo de Carapitanga, entretanto, foram interpretados apenas dois Ls associados a regressões forçadas: o primeiro limite situado entre as sequências pré-campanianas e campanianas e o segundo limite, entre as Sequências 1 e 2, comparáveis às sequências 
K-90, K100-110 e K120 e aos três cânions submarinos sugeridos por Campos Neto et al. (2007). Outro aspecto interessante e pouco discutido nos trabalhos anteriores é o caráter do preenchimento dos canais que pode ser de três tipos:

- Em onlap, marcado por formas progradacionais no centro, e agradacionais a retrogradacionais nas margens, sugerindo desconfinamento gradual do fluxo que o preenchia, com posterior abandono;

- Complexo como é o caso dos canais superpostos preenchidos por pelitos, que abarca toda a Sequência 2;

- Canais com preenchimento em offlap e downlap (c), que pode indicar maior conteúdo de arenitos.

Destaca-se o reconhecimento de um trato de sistemas transgressivo associado a lentes de arenito oriundas de leques e escorregamentos, dentro da Sequência 1, como possível candidato a rochas-reservatório (Figura 9A).

\section{Oscilações oceânicas no Cretáceo superior (Campaniano-Mastrichiano)}

Há consenso de que os principais controles sobre oscilações oceânicas globais são determinados por glaciações, pela tectônica global e pela sedimentação (e.g., Veeken, 2007; Catuneanu, 2006; Haq, 2014). Durante o período Cretáceo, tais oscilações foram interpretadas a partir de sequências deposicionais com períodos de segunda $(10-80 \mathrm{Ma})$ e de terceira ordens $(1-10 \mathrm{Ma})$ (Vail et al., 1977), tendo sido reconhecidas 58 sequências de curta duração $(0,5-3 \mathrm{Ma})$ em bacias petrolíferas de margens passivas, com variações de onlap entre 20 e $100 \mathrm{~m}$ de amplitudes (Haq, 2014). Durante o Cretáceo Inferior, as quedas do nível de base podem ter atingido aproximadamente $150 \mathrm{~m}$. Com o aumento da temperatura durante o Cretáceo Superior, teria havido ampla transferência de massas de gelo continental para os oceanos, enquanto a quebra do Gondwana teria propagado o número de margens continentais, o que condicionou o aumento do nível dos oceanos em escala global, o qual atingiu $350 \mathrm{~m}$ acima do nível do mar atual (Vail et al., 1977). Subidas dos níveis oceânicos não são incomuns nesse período, podendo ter chegado até $650 \mathrm{~m}$ acima no Cretáceo Inferior (Albiano), também no Campaniano, onde as taxas de subida podem ter variado de 10 a $90 \mathrm{~m}$ por milhões de anos (Hancock e Kauffman, 1979).

Apesar de o ciclo de segunda ordem ser comparável ao comportamento de uma curva senoide, curvas de maior frequência dentro do Cretáceo Superior continuam intrigando a comunidade científica por serem difíceis de medir (Hancock e Kauffman, 1979) e interpretar (e.g., Miller et al., 2003; Van Sickel et al., 2004; Haq, 2014), especialmente durante momentos de queda eustática (Haq, 2014).
Os estágios Campaniano-Mastrichiano, embora dentro de um período curto de $17,6 \mathrm{Ma}$ de duração, entre $83,6 \pm 0,2 \mathrm{Ma}$ e $66 \mathrm{Ma}$ (carta cronoestratigráfica internacional - IUGS-ICS 2019), têm preservado ciclos dessa ordem, com oscilações negativas da linha de costa em algumas bacias sedimentares (Miller et al., 2003; Van Sickel et al., 2004; Haq, 2014; Garcia et al., 2019; Ray et al., 2019), que os correlacionam a mecanismos de colocação de massas de gelo sobre os continentes no Cretáceo Superior. Nele estão preservadas 14 sequências, com variações do nível de base superiores a $25 \mathrm{~m}$ e duração, por vezes, inferiores a $1 \mathrm{Ma}$ (Miller et al., 2003). Especificamente, ao longo do Mastrichiano, tais variações podem ser de até $75 \mathrm{~m}$ (Ray et al., 2019).

De forma semelhante, a sedimentação nas margens passivas da costa brasileira preserva sequências deposicionais de alta frequência, oscilando entre 3 e 4 sequências, com tratos de mar baixo, registrando cânions submarinos na Bacia de Santos (e.g., Assine et al., 2008; Garcia et al., 2019) e na Bacia de Sergipe-Alagoas.

No Campo de Carapitanga (Bacia de Sergipe-Alagoas), essas flutuações estão preservadas dentro de três sequências, que apesar dos resultados ainda preliminares são comparáveis às descritas por Kominz et al. (2008), com dois picos de subida e dois de queda máxima entre a transição pré-campaniana-Campaniana (Sequência 1), incluindo ainda dois outros picos de subida, um em cada Sequência (2 e 3), e um pico de queda na Sequência 2 e dois picos na Sequência 3 ao longo do Mastrichiano. A variação da linha de costa ao longo da primeira sequência, mais ampla e de maior duração, tem duas quedas em um período de $10 \mathrm{Ma}$, semelhante à terceira ordem de frequência de 1 10 Ma de Vail et al. (1977), enquanto a variação da linha de costa da segunda e terceira sequências é de ordem de magnitude comparável com os modelos de sedimentação propostos por vários autores (Haq, 2014; Garcia et al., 2019; Ray et al., 2019) (0,5 - 3 Ma). A correlação entre essas curvas é interessante, porque favorece a hipótese de ocorrência de quedas rápidas e acentuadas para ambos os estágios, sendo condicionadas por fatores climáticos, conforme interpretado para bacias situadas em outros continentes, o que parece corroborar o controle de variação negativa por causa da glacioeustasia de curta duração (Haq, 2014).

\section{Padrões geométricos e a curva do modelo de sequências}

O principal interesse nas variações de alta frequência da linha de costa global é a possibilidade de correlacionar quedas do nível de base às modificações ambientais que condicionaram depósitos resultantes da organização geométrica de grande escala da bacia, que, por sua vez, 
preservam grandes reservas de petróleo para o período, principalmente associadas ao mar baixo. O intervalo Campaniano-Mastrichiano da Formação Calumbi é um bom exemplo da preservação dessas variações de alta frequência ao longo de três sequências deposicionais, as quais possuem características que não seguem o comportamento esperado nos modelos de sequência (Catuneanu, 2006).

A variação do nível de base ao longo das três sequências preserva um padrão pouco harmônico da curva com relação à senoide adotada como uma das premissas para construção dos modelos de arquitetura deposicional em margens passivas (e.g., Vail et al., 1977). A distribuição de padrões geométricos corrobora, em parte, aquela descrita nos modelos, nos quais observam-se uma progradação e uma retrogradação, seguidas por outra progradação, que acompanha a queda do nível de base em cada sequência (Catuneanu, 2006). É interessante notar que a Sequência 1 está completa, sendo formada por quatro tratos de sistemas deposicionais em desequilíbrio entre eventos regressivos e transgressivos, característica comum do modelo de sequências (Vail et al., 1977; Mitchum Jr. et al., 1977), no qual é maior o tempo de duração das regressões (Catuneanu, 2006). No entanto, deve-se destacar que durante o primeiro trato de mar baixo há incerteza entre formas que avançavam e recuavam, provocada, provavelmente, pelo balanço entre espaço-aporte durante a queda do nível de base (Figura 9B). Por outro lado, a Sequência 2 tem preservado somente três tratos e perdurou mais tempo durante um único evento transgressivo. Essa sequência foi separada por eventos regressivos mais curtos, caracterizados por erosão plataformal e avanço da desembocadura do sistema fluvial e aprofundamento do cânion. Ao final, a Sequência 3 tem novo desequilíbrio entre uma transgressão que dura pouco tempo e inicia de forma incomum com o trato transgressivo e é logo recoberta por geometrias progradacionais de maior duração, outro fato incomum dentro das sequências de margem passiva (Catuneanu, 2006).

\section{CONCLUSÃO}

A análise sismoestratigráfica e de perfis de poços da Formação Calumbi permitiu a definição dos limites da unidade, bem marcados por variações nos perfis de raios-gama e neutrão no topo $(874 \mathrm{~m})$ e na base $(1.679 \mathrm{~m})$, dentro dos estágios Campaniano e Mastrichiano de sedimentação. A análise de variação das antigas posições do onlap costeiro ao longo da sísmica proporcionou a elaboração de uma proposta de diagrama cronoestratigráfico, no qual são interpretadas três sequências deposicionais desarmônicas, compatíveis com sequências de períodos de curta duração $\left(3^{\mathrm{a}}\right.$ ordem, de 1 - $10 \mathrm{Ma}$ ), distribuídas em outras bacias do mundo ao longo do Cretáceo Superior.

Os intervalos de subida amplamente conhecidos para o período estão intercalados com quedas acentuadas de duração menor e variável $(0,5-3 \mathrm{Ma})$, relacionadas, possivelmente, a flutuações glacioeustáticas em decorrência da manutenção de massas glaciais que deslocaram para altas latitudes durante a fragmentação do Gondwana. Os períodos de queda do nível de base estão bem definidos pela construção de três cânions desalinhados, com 282, 202 e 120 m de espessura cada.

De acordo com o modelo aqui proposto, cada cânion é preenchido por um conjunto de sistemas deposicionais contemporâneos e organizados em três sequências, em que estão preservados um trato de estágio de queda, um trato de sistemas de mar baixo, um trato de sistemas transgressivos e um trato de mar alto.

Do ponto de vista de análise de sequências estratigráficas, a primeira sequência obedece de forma equilibrada o número de quedas e subidas do nível de base, tendo sido interpretadas duas progradações e duas retrogradacões de geometrias deposicionais. Contudo, o tempo de permanência de tratos retrogradacionais parece ter sido menor, o que é consistente com o modelo de sequências. Ao longo do Campaniano desenvolveu-se o primeiro vale inciso, preenchido por um TSMB e logo transgressivo, com preservação de sismofácies sugestivas de leques submarinos lamosos no centro, que paulatinamente desconfinavam para as margens, conforme aumentava o espaço de acomodação, onde, por vezes, preservam-se fluxos gravitacionais de arenitos e escorregamentos.

A segunda sequência é menos espessa e compreende duas progradações e uma regressão, tendo sido relacionada a duas quedas sucessivas curtas do nível de base, marcadas pelo desenvolvimento de dois cânions, que se sobrepõem e se deslocam lateralmente pelo preenchimento do canal lamoso.

A terceira sequência tem poucas informações e é pouco precisa, sendo representada pela migração de formas de leito arenosas em um contexto de regressão normal e um trato de estágio de queda mal desenvolvido.

O contraste temporal entre a duração de sistemas retrogradacionais e progradacionais na sequência evidencia comportamento que se contrapõe àquele adotado nas premissas de variação do nível eustático do modelo.

A configuração geométrica do Campo de Carapitanga obedece, em parte, aos modelos propostos para áreas situadas poucos quilômetros mais ao norte. Neste campo não foi identificada a sequência de topo, e os cânions parecem ter maior complexidade interna e externa. Eles podem atingir $10 \mathrm{~km}$ de extensão lateral; contudo, o cânion da Sequência 1, mais profundo e preenchido por leques e 
escorregamentos laterais arenosos, é um dos melhores candidatos a rochas-reservatório, enquanto os demais da Sequência 2 são mais rasos e estão organizados e quase superpostos. Essa mudança lateral pode ser atribuída a um aporte de leques advindos do NW, oblíquos à seção, o que sugere uma mudança de direção das incisões da plataforma em relação às áreas mais ao norte dos modelos anteriores.

\section{AGRADECIMENTOS}

Os autores agradecem à Agência Nacional do Petróleo (ANP), a disponibilização de dados bibliográficos e arquivos de linhas sísmicas, e à Empresa de Engenharia de petróleo Ltda (ENGEPET), por ter cedido dados litológicos e geofísicos de poços do Campo de Carapitanga. Agradecem também ao Programa de Pós-Graduação e Análise de Bacias (PGAB-UFS), em que foi realizado o mestrado que resultou nesta contribuição. Por fim, agradecem aos revisores anônimos, as contribuições durante o processo de análise do manuscrito.

\section{REFERÊNCIAS}

Agência Nacional do Petróleo, Gás Natural e Biocombustíveis (ANP). (2005). Resumo para $7^{a}$ Rodada de Licitações. Área de Carapitanga, Rio de Janeiro. Rio de Janeiro: Agência Nacional do Petróleo, Gás Natural e Biocombustíveis. $10 \mathrm{p}$.

Assine, M. L., Corrêa, F. S., Chang, H. K. (2008). Migração de depocentros na Bacia de Santos: importância na exploração de hidrocarbonetos. Revista Brasileira de Geociências, 38(2 Supl.), 111-127. https://doi. org/10.25249/0375-7536.2008382S111127

Bouma, A. H. (2000). Coarse-grained and fined-grained turbidite systems as end member models applicability and dangers. Marine and Petroleum Geology, 17(2), 137-143. https://doi.org/10.1016/S0264-8172(99)00020-3

Bulhões, E. M. (1999). Técnica "volume de amplitudes" para mapeamento de feições estruturais. $6^{\text {th }}$ International Congress of the Brazilian Geophysical Society. Anais... SBGf, 296p.

Bulhões, E., Amorim, W. (2005). Princípio da SismoCamada Elementar e sua aplicação à Técnica Volume de Amplitudes (tecVA). 9th International Congress of the Brazilian Geophysical Society \& EXPOGEF, 1382-1387. SBGf. https://doi.org/10.1190/sbgf2005-275
Cainelli, C. (1992). Sequence stratigraphy, canyons, and gravity mass flow deposits in the Piaçabuçu Formation, Sergipe-Alagoas Basin, Brazil. Tese (Doutorado). Austin: University of Texas.

Campos Neto, O. P. A, Souza-Lima, W., Cruz, F. E. G. (2007). Bacia de Sergipe-Alagoas. Boletim de Geociências Petrobras, 15, 405-415.

Catuneanu, O. (2006). Principles of Sequence Stratigraphy. Edmonton: Elsevier.

Emery, D., Myers, K. J. (1996). Sequence Stratigraphy. Oxford: Blackwell Science, 297 p.

Feijó, F. J. (1994). Bacias de Sergipe e Alagoas. Boletim de Geociências da Petrobras, 8(1), 149-161.

Figueiredo, A. M. N., Martins, C. C. (1990). 20 anos de exploração da Bacia de Campos e o sucesso nas águas profundas. Boletim de Geociências da Petrobras, 4(1), 105-123.

Figueiredo, M. N. (2014). Modelos deposicionais comparados dos reservatórios areníticos santonianos-campanianos da Formação Calumbi, bacia Sergipe-Alagoas. Dissertação (Mestrado). São Cristóvão: Programa de Pós-Graduação em Geociências e Análises de Bacias, Universidade Federal de Sergipe.

Galloway, W. E. (1989). Genetic stratigraphic sequences in basin analysis, I: Architecture and genesis of floodingsurface bounded depositional units. American Association of Petroleum Geologists Bulletin, 73(2), 125-142. https://doi. org/10.1306/703C9AF5-1707-11D7-8645000102C1865D

Garcia, A. M., Pires, C. A., Münch, D., Carvalho, I. F. P., Freitas, L. S., Valore, L. A., Silva, C. E., Lima, R. N., Balensiefer, D. F., Vesely, F. F. (2019). Recognizing Late Cretaceous to Paleoene changes in relative sea level in nothern Santos basin, Brazil. Brazilian Journal of Geophysics, 37(2), 1-11. https://doi.org/10.22564/rbgf.v37i2.1999

Hancock, J. M., Kauffman, E. G. (1979). The great transgressions of the Late Cretaceous. Journal of the Geological Society, 136(2), 175-186. https://doi.org/10.1144/ gsjgs.136.2.0175

Haq, B. U. (1993). Deep sea response to eustatic change and significance of gas hydrates for continental margin stratigraphy. In: H. W. Posamentier, C. P. Summerhayes, B. U. Haq, G. P. Allen (Eds.), Sequence Stratigraphy and Facies Associations, 18, p. 93-106. Oxford: Blackwell Science, Special Publication. 
Haq, B. U. (2014). Cretaceous eustasy revisited. Global and Planetary Change, 113, 44-58. https://doi.org/10.1016/j. gloplacha.2013.12.007

Jardim de Sá, E. F., Medeiros, W. E., Antunes, A. F., Lins, F. A. (2008). Revisão Geológica e Reavaliação dos Sistemas Petroliferos da Bacia Sergipe-Alagoas. Natal: Agência Nacional do Petróleo.

Kearey, P., Brooks, M., Hill, I. (2009). Geofisica de Exploração. São Paulo: Oficina de Textos.

Kominz, M. A., Browning, J. V., Miller, K. G., Sugarman, P. J., Mizintseva, S., Scotese, C. R. (2008). Late Cretaceous to Miocene sea-level estimates from the New Jesey and Delaware coastal plain boreholes: an error analysis. Basin Research, 20(2), 211-226. https://doi.org/10.1111/j.1365-2117.2008.00354.x

Koutsoukos, E. A. M., Beurlen, G. (1991). Análise paleobiocenótica de foraminíferos bentônicos do Cretáceo Superior da Bacia de Sergipe pelo método Braun-Blanquet. Boletim de Geociencias Petrobras, 5(1/4), 5-16.

Miall, A. D. (2000). Principles of Sedimentary Basin Analysis. Heidelberg: Springer.

Miall, A. D. (2010). The Geology of Stratigraphic Sequences. Heidelberg: Springer.

Miller, K. G., Sugarman, P. J., Browning, J. V., Kominz, M. A., Hernández, J. C., Olsson, R. K., Wright, J. D., Feigenson, M. D., Sickel, W. V. (2003). Late Cretaceous chronology of large, rapid sea-level changes: glacio eustasy during the greenhouse world. Geology, 31(7), 585-588. https://doi. org/10.1130/0091-7613(2003)031<0585:LCCOLR >2.0.CO;2

Mitchum Jr., R. M. (1977). Seismic stratigraphy and global changes of sea level, part 11: glossary of terms used in seismic stratigraphy. In: C. E. Payton (Ed.), Seismic StratigraphyApplications to Hydrocarbon Exploration, 205-212. Tulsa: AAPG-Memoir, 26.

Mitchum Jr., R. M., Wagoner, J. C. V. (1991). Highfrequency sequences and their stacking patterns: sequencestratigraphic evidence of high-frequency eustatic cycles. Sedimentary Geology, 70(2-4), 131-160. https://doi. org/10.1016/0037-0738(91)90139-5

Plint, A. G., Nummedal, D. (2000). The falling stage systems tract: recognition and importance in sequence stratigraphic analysis. In: D. Hunt, R. L. Gawthorpe, (Eds.), Sedimentary Response to Forced Regression, 1-17. Londres: Geological Society. Special Publication, 172.
Ponte, F. C., Potter, P. E., Toffoli, L. C., Barros, M. C. (1975). Gênese e distribuição dos arenitos Calumbi na foz do rio São Francisco, Bacia Sergipe-Alagoas. Petrobras, Relatório Interno. Rio de Janeiro: Petrobras.

Posamentier, H. W., Walker, R. G. (2006). Facies Models Revisited. Tulsa: Society for Sedimentary Geology, Especial Publication, 84.

Rancan, C. C., Lira, F. S., Nishimura, E. M., Araújo, A. L. N. (2009). O soerguimento do domínio Macururé e sua influência na sedimentação turbidítica no Crétaceo Superior da Sub-bacia de Sergipe, Bacia de Sergipe-Alagoas. Boletim de Geociências Petrobras, 17, 45-67.

Ray, D. C., Van Buchem, S. P., Baines, G., Davies, A., Gréselle, B., Simmons, M. D., Robson, C. (2019). The magnitude and cause of short-term eustatic Cretaceous sea-level change: a synthesis. Earth-Science Reviews, 197, 102901. https://doi.org/10.1016/j.earscirev.2019.102901

Reading, H. G. (1996). Sedimentary Enviroments: Process, Facies and Stratigraphy. Oxford: Blackwell Science. 326 p.

Ronzê, P. C. (1995). Petrologia e características de reservatórios dos turbiditos cretácicos da Formação calumbi, bacia de Sergipe-Alagoas, Brasil. Dissertação (Mestrado). Ouro Preto: Programa de Pós-Graduação em Evolução Crustal e Recursos Naturais da Escola de Minas, Universidade Federal de Ouro Preto.

Schaller, H. (1969). Revisão Estratigráfica da Bacia de Sergipe-Alagoas. Boletim Técnico da Petrobras, 12, 21-86.

Sangree, J. B., Widmier, J. M. (1977). Seismic stratigraphy and global changes in sealevel Part 9: seismic interpretation of clastic depositional facies, 165 184. In: Payton (Ed.), Seismic Stratigraphy: Application to Hydrocarbon Exploration, 53-62. Tulsa: AAPGMemoir, 26.

Selley, R. C. (2001). Applied Sedimentology. Londres: Academic Press.

Silva, B. O. (2007). Evolução, geometria e preenchimento do complexo de canyons de Brejo Grande, Bacia de Sergipe-Alagoas. Dissertação (Mestrado). Porto Alegre: Programa de Pós-Graduação em Geociências, Instituto de Geociências, Universidade Federal do Rio Grande do Sul. 
Siqueira, M., Santos, R. C. C. (2008). Os campos maduros de petróleo e o desenvolvimento regional: o caso do nordeste brasileiro. XVII Congresso Nacional do CONPEDI, Brasília. Anais...

Souza-Lima, W. (2001). Macrofaunas campanianas e ambientes deposicionais da Formação Calumbi, bacia de Sergipe-Alagoas, Brasil. Tese (Doutorado). Rio de Janeiro: Programa de Pós-Graduação em Geologia, Instituto de Geociências, Universidade Federal do Rio de Janeiro.

Teixeira, L. R., Lima, E. S., Neves, J. P., Santos, R. A., Santiago, R. C., Melo, R. C. (2014). Mapa Geológico e de Recursos Minerais do Estado de Sergipe. Escala 1:250:000. Brasil, Ministério de Minas e Energia. Secretaria de Geologia, Mineração e Transformação Mineral.
Vail, P. R., Mitchum, R. M., Todd, R. G., Widmer, J. M., Thompson, S., Sangree, J. B., Bubb, J. N., Hatfield, W. G. (1977). Seismic stratigraphy and global changes in sea level. In: Payton (Ed.), Seismic Stratigraphy: Application to Hydrocarbon Exploration, 49-212. Houten, Holanda: EAGE (European Association of Geocientists \& Engineers).

Van Sickel, W. A., Kominz, M. A., Miller, K. G., Browning, J. V. (2004). Late Cretaceous and Cenozoic sea-level estimates: backstripping analysis of borehole data, onshore New Jersey. Basin Research, 16(4), 451-465. https://doi. org/10.1111/j.1365-2117.2004.00242.x

Veeken, P. C. H. (2007). Seismic Stratigraphy, Basin Analysis And Reservoir Characterization. In: K. Helbig, S. Treitel (Eds.), Handbook of Geophysical Exploration: Seismic Exploration, 37, 111-234. Oxford: Elsevier. 